\title{
A Comprehensive Review of Recent Advances in Smart Grids: A Sustainable Future with Renewable Energy Resources
}

\author{
Ibrahim Alotaibi $^{1}\left(\mathbb{D}\right.$, Mohammed A. Abido $^{1,2} \mathbb{D}$, Muhammad Khalid ${ }^{1,2}\left(\mathbb{D}\right.$ and Andrey V. Savkin ${ }^{3, *(D)}$ \\ 1 Electrical Engineering Department, King Fahd University of Petroleum \& Minerals (KFUPM), \\ Dhahran 31261, Saudi Arabia; alotaibi.ib@gmail.com (I.A.); mabido@kfupm.edu.sa (M.A.A.); \\ mkhalid@kfupm.edu.sa (M.K.) \\ 2 K.A.CARE Energy Research \& Innovation Center, Dhahran 31261, Saudi Arabia \\ 3 School of Electrical Engineering and Telecommunications, University of New South Wales (UNSW), \\ Sydney, NSW 2052, Australia \\ * Correspondence: a.savkin@unsw.edu.au; Tel.: +61-2-9385-6359
}

Received: 22 October 2020; Accepted: 20 November 2020; Published: 27 November 2020

\begin{abstract}
The smart grid is an unprecedented opportunity to shift the current energy industry into a new era of a modernized network where the power generation, transmission, and distribution are intelligently, responsively, and cooperatively managed through a bi-directional automation system. Although the domains of smart grid applications and technologies vary in functions and forms, they generally share common potentials such as intelligent energy curtailment, efficient integration of Demand Response, Distributed Renewable Generation, and Energy Storage. This paper presents a comprehensive review categorically on the recent advances and previous research developments of the smart grid paradigm over the last two decades. The main intent of the study is to provide an application-focused survey where every category and sub-category herein are thoroughly and independently investigated. The preamble of the paper highlights the concept and the structure of the smart grids. The work presented intensively and extensively reviews the recent advances on the energy data management in smart grids, pricing modalities in a modernized power grid, and the predominant components of the smart grid. The paper thoroughly enumerates the recent advances in the area of network reliability. On the other hand, the reliance on smart cities on advanced communication infrastructure promotes more concerns regarding data integrity. Therefore, the paper dedicates a sub-section to highlight the challenges and the state-of-the-art of cybersecurity. Furthermore, highlighting the emerging developments in the pricing mechanisms concludes the review.
\end{abstract}

Keywords: demand response in microgrids; energy data management and cybersecurity; energy pricing and bidding framework; intelligent multi-agent system; optimal management of energy mix; optimization techniques for smart grids; price forecasting; reliability assessment; topological indices of smart grids

\section{Introduction}

The stipulation on sustainable modernization of the energy sector primarily brought about the need to establish deregulation in the power industry. Among several novel propositions, the concept of microgrids proves to be the most promising solution [1]. Microgrids (MG) are small-scale electrical distribution networks consisting of distributed generators (renewable and/or non-renewable generators), heterogenous loads, and energy storage devices that operate in grid-connected or islanded modes with suitable interfacial power electronic devices [2]. Descriptively, MGs in the form of autonomic grids are existent in remote communities wherein interconnection to utility networks is techno-economically 
inconceivable. The power delivered by renewable energy sources in the early stages of integration was infinitesimal in comparison to existing conventional generators and, hence, their impact on the power network was inherently unnoticeable.

However, with recent developments and commitments toward renewable and sustainable power generation, renewable energy sources (RES) such as solar photovoltaics, wind, hydropower, and hydrogen technologies are among the most popular and prioritized integrations to the electrical power network. Therefore, microgrid facilitates flexibility to consolidate appropriate control scheme and power management algorithm to maintain the quality of power supplied by transient RES through power electronic interventions [3]. Power electronic devices primarily provide the flexibility to integrate numerous distinctive forms of RES, energy storage devices, and heterogeneous loads. Furthermore, numerous conceptualized topologies of power electronic converters/inverters are proposed [4-6] to establish a point of common coupling (PCC) that plays a key role in the formation of DC, AC, and hybrid AC-DC microgrids for various domains of voltage and frequency levels. In this respect, several power electronic interfacing configurations and topologies have been proposed to not only achieve a diversified power generation framework but also enable MGs to effectively manage the power and energy flow $[7,8]$.

Accordingly, with large-scale integration of RES technologies and subsequent deregulation, the overall operation needs to be carefully monitored accompanied by power management frameworks to support and facilitate controllable power sharing and load sharing [9]. Consequently, the paradigm adaptation of microgrids for large-scale integration of distributed renewable energy sources will allow a structuralized and intensive solution for numerous challenges associated with deregulated power networks that will extensively reduce the need for complex centralized coordination and facilitate the formation and realization of the smart grids.

Smart Grid (SG) does not have a unique definition to precisely describe the phenomena [10]. However, the smart grid can be simply defined as an intelligent network that is automated and able to store, communicate, and make decisions. A similar definition of smart grids is dictated by the US Energy Independence and Security Act 2007 [11]. It defines the smart grid as a modernization to the electrical network such that it monitors, increases grid resiliency to disruptions, and automatically optimizes grid operation of interconnected system components starting from central generating units and distributed generation through transmission networks up to load centers. In addition, the US National Institute of Standards and Technologies (NIST) [12] describes the smart grid as "a modern grid that adapts bi-directional flows of energy" and utilizes two-way communication and control capabilities that lead to a wide range of new functionalities and applications. It adds, unlike today's grid in which the energy is delivered from generation centers to demand centers, Smart grids allow a two-way flow of energy and data. The definition of the smart grid has been stated by numerous entities and researchers, as given in References [13-21]. They, however, are conceptually united on the general framework of the term.

Furthermore, the US-based Electric Power Research Institute (EPRI) [16] defines the smart grid as "the transition from the current grid where the flow of power is permitted from the central generation to load locations into a grid where there is a peer to peer consumer interactions, distributed generation, and control centers". In the UK, the Department of Energy and Climatic Change emphasizes that with a smarter grid, operators are more aware of supply-demand balance information, which in turn helps to intelligently manage the system and shift the demand from peaking instants to off-peak periods [17]. An initiative is launched in Australia called "SmartGrid SmartCity" between Energy Australia and Ausgrid, and the Australian government echoes EPRI's definitions, defines the smart grid as a novel and a highly intelligent way of supplying electricity. It incorporates advanced communication infrastructure, innovative sensing, and metering technologies with the electrical network to create a two-way, interactive grid. Smart sensing technologies help to achieve fewer grid disruptions and outages. Moreover, smart metering may help consumers to manage their energy consumption to 
reduce billing costs effectively. The development and the emerging trends in smart grids have been highlighted in References [22-34].

The smart grid shifts the current conventional grid into a more modernized grid that can function cooperatively and responsively. Users, generators, and consumers may intelligently be integrated into the grid to provide efficient, secure, and economically feasible supplies [18]. The SG incorporates distributed intelligence, bi-directional-based infrastructure for communications, and power flow to improve system efficiency, reliability, and sustainability. Furthermore, the smart grid is a network that integrates digital computing capabilities and highly automated services into the already existing power system infrastructure. Empowering the transition toward the smart grid enhances the robustness and self-healing capabilities of the system, according to Reference [20]. Table 1 briefly illustrates the major differences between the conventional power grid and the smart grid. SGs require an effective deployment to the information and communication technology to have a successful implementation of this concept. Upgrading the conventional power grid toward an active network of a two-way communication capability is one of the main barriers in smart grids (SGs). In accordance with the diversification of the power network, a smooth transition to incorporate SG technologies has been done with appropriate categorical standardization [35-44].

Table 1. Conventional grid versus smart grid [15].

\begin{tabular}{cc}
\hline Conventional Grid & Smart Grid \\
\hline Mechanically operated & Digitized \\
Unilateral & Bi-directional \\
Centralized Power generation & Distributed Generation \\
Radially connected & Dispersed \\
Small number of sensors & Many \\
Less monitoring capabilities & Highly monitored \\
Manual control & Automated control \\
Less security issues & Vulnerable to security issues \\
Slow responsive actions & Fast response \\
\hline
\end{tabular}

The remaining of the paper is structured as follows: Section 2 reviews the structure and the main characteristics of SGs. Furthermore, the essential technologies that may facilitate the transition toward a highly functioned infrastructure are highlighted. From a power system perspective, the main components in smart grids are thoroughly, independently studied in Section 3. Moreover, the recent advances in reliability and resiliency indices in smart grids are presented throughout Section 3. The energy data management and cybersecurity in smart grids are reviewed in Section 4. In Section 5, we thoroughly investigate the pricing mechanisms in smart grids. Figure 1 briefly emphasizes the organization of the paper.

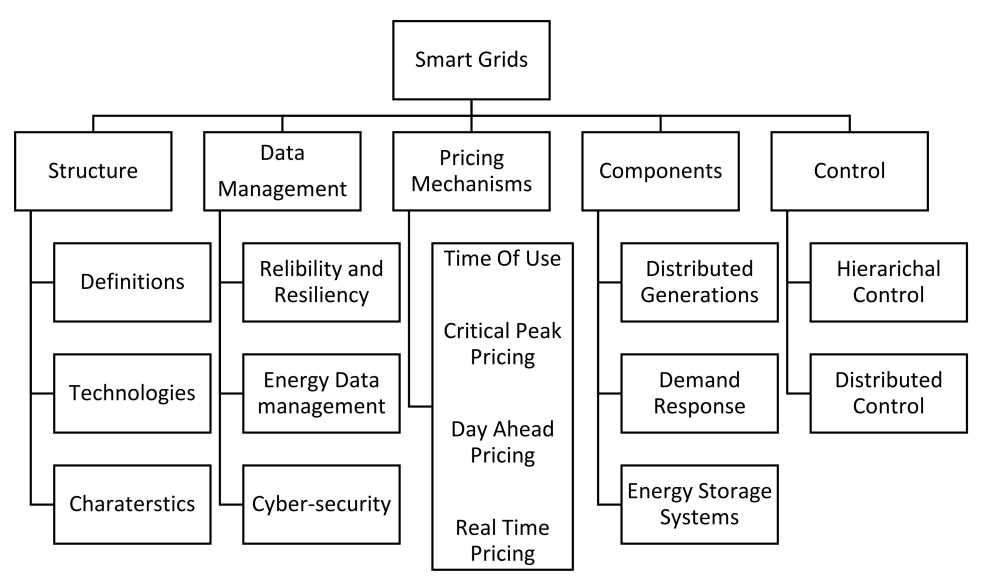

Figure 1. The organization of the paper at a glance. 


\section{Structure of Smart Grids}

\subsection{Definitions}

The National Institute of Standards and Technology (NIST) [12] has classified smart grids into seven categories and (sub-categories) that comprise actors and applications. Actors may include devices (e.g., renewable energy generation, and smart meters), control systems, programs, decision-makers (stakeholders), and telecom stations (data-exchange). The applications are known as the tasks that can be performed by actors within the category (e.g., energy management, site automation, and energy storage) or between different categories. Actors in the same category may interact with actors in other categories, and a specific category may contain components from other categories (i.e., distribution utility may contain actors from operation category such as Distribution Management System and in the customer category such as electric meters. A detailed classification is presented in Table 2.

Table 2. Classification and elements of smart grids [12,15].

\begin{tabular}{cl}
\hline Category & \multicolumn{1}{c}{ Description and the Actors in Domain } \\
\hline Customer & $\begin{array}{l}\text { Where the electricity is consumed, End-users. The sub-category } \\
\text { includes domestics and large consumers, such as commercial and } \\
\text { industrial loads. Actors can generate, manage, and store. }\end{array}$ \\
\hline Market & $\begin{array}{l}\text { Where the assets are exchanged. The operator and participants are the } \\
\text { actors in electricity markets. }\end{array}$ \\
\hline Service Provider & $\begin{array}{l}\text { An organization that provides services pertaining to the establishment } \\
\text { and secure operation of smart grids as per the requirements of the } \\
\text { consumers and utilities. }\end{array}$ \\
\hline Operations & $\begin{array}{l}\text { The proper operation of the power system is monitored-the managers } \\
\text { of the flow of electricity. }\end{array}$ \\
\hline Bulk Generation & $\begin{array}{l}\text { Where the delivery of bulky electricity to consumers starts, actors are } \\
\text { the generators of electricity in bulk quantities; energy can also be stored } \\
\text { for later distribution. }\end{array}$ \\
\hline Transmission & $\begin{array}{l}\text { Where the bulky power is transferred from generation centers to } \\
\text { distribution. Actors are the carriers of electricity and may also generate } \\
\text { and store electricity. }\end{array}$ \\
\hline Distribution & $\begin{array}{l}\text { Where Distributed Generation, Distributed Storage, transmission, and } \\
\text { consumers' interconnect. Actors are the entities that distribute electricity } \\
\text { to and from customers. }\end{array}$ \\
\hline
\end{tabular}

\subsection{Smart Grid Technologies}

Numerous technologies can be implemented to achieve successful control and automation in smart grids $[21,45]$. Such technologies are imperative to facilitate the transition toward a well-functioned infrastructure from the perspective of grid designers and consumers. These technologies may include Automatic Voltage Regulation (AVR), Energy Management System (EMS), Automatic Generation Control (AGC), Advanced Metering Infrastructure (AMI), Meter Data Management (MDM), Distribution Management System (DMS), Geographical Information System (GIS), Outage Management System (OMS), Wide Area Management System (WAMS), and Demand Side Management (DSM). Some of these technologies are highlighted in Table 3.

AVR helps to keep the voltage profiles within the allowable limit, whereas EMS ensures the reliability and secures the operating points for the Supervisory Control and Data Acquisition (SCADA). It could also be considered as a large-scale optimizer for the entire grid. AGC has a vital role in grid stability as it performs optimal load distribution among the generating units to re-gain stability margins. The smart meters allow two-way communication between the end-users and the service provider [15]. This enables consumers to control their energy usage and ensures more accurate billing. In addition, smart meters can provide power outage notifications and power quality monitoring. For a demand 
to be controllable, smart meters are often used since they possess a two-way communication that allows system operators or aggregators to effectively control the loads [46,47]. For instance, the authors in Reference [46] investigated the ability of smart meters to control domestic demands for frequency regulation purposes. Due to the slow response of communicating channels during frequency surges, an alternative control scheme was proposed, while in Reference [25], a smart meter based controlled load blocking scheme for domestic loads was proposed for primary frequency control considering end-users' lifestyles and safety. The advanced metering infrastructure (AMI) is a fundamental step toward grid modernization. AMIs are not a single technology, rather an integration of a wide range of technologies that can intelligently communicate between consumers and system operators. The AMI provides the necessary information for consumers to make intelligent decisions and the ability to execute those decisions that lead to substantial benefits they do not currently have. The AMI and distribution automation facilitates a more modernized grid through transformers and feeders monitoring, outage management, and integration of electric vehicles. MDM supports the decision-making process and assists in managing the flow of data.

DMS performs several applications, such as efficient controlling and monitoring of the distribution network. It acts as a decision support system that helps personnel in taking the counteractions once an outage occurs. It may also help in maintaining the voltage and frequency within their nominal values. DMS can also be used to provide the needed functionality for consumers to control their appliances once required. GIS provides the necessary infrastructure that integrates the data onto geographical maps. GIS visualization is an extremely crucial component in smart grids. OMS helps to restore the functionality of the system post outages. WAMS assists in grid synchronization in a high voltage network. It can be utilized to provide disturbance analysis and verification of Flexible AC Transmission Systems (FACTS) [48]. WAMS can also be used to provide time measurements through Phasor Measurement Units (PMUs) [49-51]. DSM offers intelligent energy curtailment and will be thoroughly investigated in the sequel of this paper.

Table 3. Smart grids technologies and applications at a glance [21].

\begin{tabular}{|c|c|c|c|c|}
\hline Technique & Ref. & Year & Author (s) & Objective \\
\hline \multirow{2}{*}{ AVR } & {$[52]$} & 2014 & Ting-Chia et al. & $\begin{array}{l}\text { (a) Hybrid protocol for AVR } \\
\text { (b) Power control using FLC }\end{array}$ \\
\hline & [53] & 2010 & Morris et al. & $\begin{array}{l}\text { (a) AVR control based on sensitivity } \\
\text { (b) Voltage regulation }\end{array}$ \\
\hline \multirow{2}{*}{ GIS } & [54] & 2012 & Schneider Electric & $\begin{array}{l}\text { (a) Efficient smart grid strategies based on GIS } \\
\text { (b) Data accuracy } \\
\text { (c) Time reduction } \\
\text { (d) Efficient workflow }\end{array}$ \\
\hline & {$[55]$} & 2009 & Esri Inc & $\begin{array}{l}\text { (a) Providing the necessary tools for network } \\
\text { modeling and component tracing. }\end{array}$ \\
\hline \multirow{2}{*}{ OMS } & {$[56]$} & 2013 & John Dirkman & $\begin{array}{l}\text { (a) OMS for normal operations and emergencies } \\
\text { (b) OMS assists in advanced analysis and control } \\
\text { of the smart grid. } \\
\text { (c) Prediction roadmap }\end{array}$ \\
\hline & [45] & 2011 & Eduardo et al. & $\begin{array}{l}\text { (a) Power restoration } \\
\text { (b) Automated solutions for reporting problems. }\end{array}$ \\
\hline \multirow{2}{*}{ AGC } & {$[53]$} & 2014 & Siddaharth et al. & $\begin{array}{l}\text { (a) Investigate the impact of data } \\
\text { (b) Attack detection }\end{array}$ \\
\hline & [57] & 2012 & Ali et al. & $\begin{array}{l}\text { (a) Smart grid intermittency mitigation } \\
\text { (b) High-frequency fluctuations control }\end{array}$ \\
\hline
\end{tabular}


Table 3. Cont.

\begin{tabular}{|c|c|c|c|c|}
\hline Technique & Ref. & Year & Author (s) & Objective \\
\hline AMI & {$[45]$} & 2011 & Eduardo et al. & $\begin{array}{l}\text { (a) Data Gathering cost reduction } \\
\text { (b) Connection and disconnection of end-users }\end{array}$ \\
\hline EMS & {$[58]$} & 2012 & Rahman et al. & $\begin{array}{l}\text { (a) Backup batteries } \\
\text { (b) Efficient operation of EMS }\end{array}$ \\
\hline
\end{tabular}

\subsection{Characteristics of Smart Grids}

The following bullet points briefly summarize the main characteristics of smart grids that have been reported in the literature [59-61]:

1. Integrable Distributed Resources (DER) that include sustainable energy sources.

2. Should perform dynamic optimization of grid operation continuously.

3. Should have digitized information and control technologies to enhance the reliability and efficiency of the electric network.

4. Should have Demand Side Response (DSR) programs and demand-side resources.

5. Integrable smart appliances.

6. Are fortified against cyber threats.

7. Should have advanced storage devices and peak-shaving technologies, including hybrid and plug-in electric vehicles.

\subsection{Benefits of Smart Grid Transformation}

Utilities are encouraged to efficiently generate and distribute their electricity with a minimal negative impact on the environment. This practice is not only a matter of good corporate citizenship, but some countries also impose a wide range of regulations to limit carbon emissions, and they offer incentives for those transforming their infrastructures to a modernized network. For instance, in Europe, the well-known principle "Cap and Trade" limits the total amount of greenhouse gas productions from power plants and factories. A utility is free to operate as long as its carbon emission allowance is below the cap level. Moreover, a company may trade its spare allowance to a company that violates its assigned cap level. The principle is applied in European states in addition to Iceland, Norway, and Liechtenstein [62]. On the other hand, In the United States, 40\% of greenhouse gas emissions are produced from electricity consumption. By 2030, it is estimated that smart grid-based applications that range from shallower domains like voltage control to broader domains like the integration of renewable energy resources would reduce the nation's carbon dioxide emissions from 211 to 60 million metric tons annually $[11,16]$. Although the transformation toward smart grids may unfold over a long period, the incremental progress in that area yields the major pros listed below, which are highlighted in References [63-69]. The application of a modernized network would:

- Improve the reliability and quality of the power grid.

- Optimize the operation of existed assets to avert the future expansion of backup plants.

- Enhance the overall system efficiency.

- Improve system resiliency.

- Facilitate the incorporation of Distributed Resources.

- Enable predictive maintenance and self-healing capacities.

- Lower greenhouse gaseous emissions.

- Increase consumers' assortments.

- Increase the opportunities to enhance system security. 


\section{Smart Grid Predominant Components}

\subsection{Distributed Generation}

The conventional paradigm of the well-known centralized power grid is being reshaped due to the high penetration of Distributed Generation (DG). The advent of distributed generation has disrupted the way power is generated and supplied to the electrical grid. The lack of fossil fuels, increased greenhouse emissions, and the automation that has been evolving in informatics and technologies have contributed to the revival of the DG. Researchers believe that DG has a vital role in forming the future of the electrical grid in addition to the storage technologies and demand response [70-73]. However, the degree of change in the future power grid is somewhat ambiguous since it mainly relies on the extent of DGs deployment that may reach. Furthermore, the precise role of DGs is still debatable and needs to be thoroughly addressed in order to have a comprehensive visualization of how things might evolve in the future. For instance, the authors of Reference [70] have devoted their article to investigate the role of DGs in shaping the future power grid.

The definition of DGs in the literature is somewhat opaque [70] as there is no exact definition to describe the term adequately. The resources $[74,75]$ define the DGs as small-scale and renewable-based units that are geographically confined near the load centers. DGs may also involve large-scale units that are not friendly-based resources. In Reference [76], the authors defined the DGs as electric power sources that are physically connected to a distribution network or at the meter-side of consumers. In Reference [77], the authors classified the DGs, cogeneration, backup generation, storage capabilities, and microgrids under the category of Distributed Energy Resources (DER). Distributed Energy Resources are relatively small capacity sources that can be deployed to meet regular loads. The integration of such resources may facilitate the transition toward smart grids. The need to replace the fossil fuel generators and the mitigation of growing demands can be met by the deployment of Renewable Energy Sources (RESs). However, processing such aggregated sources require a tremendous amount of data that needs intelligent control capabilities.

However, the most prevailing and cited factor that motivated the expansion of DGs is the greenhouse emission reduction [78-80]. Furthermore, the growth in electrical demands [81,82], governmental regulations [83,84], market liberalization [85], and lower capital costs [86-88] was reported among the motivating factors to the deployment of DGs. The deployment of DGs may also provide a wide range of technical benefits if their size, location, and operation are properly optimized [70]. Furthermore, DGs may contribute to network losses reduction if installed close to the load centers [89-93], improve voltage profile as reported in References [94-97], enhance systems' reliability [98-100], and provide computational flexibility for system controllability especially pertaining to generation [101-103] and demand-side management [104-106].

Due to the advances in technologies and the rapid expansion of sustainable resources and resiliency concerns, DER constitutes the backbone of the future grid infrastructure. According to Reference [107], the DER capacity is expected to rise from 134 GW by the end of 2017 to approximately 528.4 GW in 2026 due to distributed Solar PV, small to medium-scale wind turbines, microturbines, fuel cells, Electric Vehicles (EVs), Distributed Energy Storage (DES), and demand response (DR). For instance, the total installed capacity of DER constituted $2 \%$ of the overall installed capacity in the United States [108]. Distributed PV accounted for $12 \%$ of those installed in 2016. For example, California plans to integrate $12 \mathrm{GW}$ of DER by 2020. For further details on the progress of DER in the United States, interested readers are referred to Reference [108]. In China, by the end of June 2017, the total installed capacity of distributed PVs was $16.15 \mathrm{GW}$, which constituted $17 \%$ of the overall PV installed capacity [109].

\subsection{Reliability Assessment of DGs in Modern Grids}

The electrical power grid is very complex and highly integrated. Failure in any part of the system exposes the network to catastrophic consequences. However, there are several terms associated with 
reliability studies such as vulnerability, resiliency, robustness, and security. The reliability of the power system is commonly used to encompass all these metrics. The authors of References [69,110-121] have intensively investigated the reliability assessment for smart grid purposes. The reliability is often measured differently at the transmission, generation system, and distribution levels. That is, the Average Interruption Frequency Index (SAIFI) and the System Average Interruption Duration Index (SAIDI) are used at the distribution level. SAIFI is used to quantify the average frequency of outages per consumer, whereas SAIDI is dedicated to measuring the average duration of outages [122-124]. On the other hand, at the bulk generation level, the term Loss of Load Expectation (LOLE) is used to describe the energy demanded that remains unserved over a period of time. Recently, the term resiliency has been frequently used in the literature. EPRI [125] defines resiliency as the ability of the grid to quickly recover after low and high-frequency events. Such events (e.g., cyber attacks or physical attacks, natural events, and severe geomagnetic disturbances) devastate the entire electrical grid.

In order to realize the impact of DGs installment on the reliability indices, the available capacity of the DG unit that assists in restoring the disrupted supply needs to be determined beforehand for reliability analysis [126]. However, the following attributes should be considered when carrying out reliability assessment studies:

- The availability of the DG: Distributed generation units are exposed to failures that might restrict their functionality. Therefore, reliability models should consider the availability of DGs under different contingency scenarios. Such models require probabilistic approaches to deal with such a kind of stochasticity.

- The operating mode of DGs (Islanded and grid-connected): In Islanded mode, the lack of appropriated control, protection capabilities, and communication infrastructure limits this kind of operation [126]. However, numerous studies have been proposed to address the reliability assessment of the distribution network to facilitate the transformation toward the intelligently managed grid. Whereas in grid-connected mode, DGs are installed close to the load centers to improve the reliability of the system by partially relieving the centralized units during heavy loading conditions. It is, therefore, necessary to quantify the power exchange between the feeders under the presence of DGs. A summary of the prevailing techniques within the layout of microgrids is highlighted in Tables 4 and 5.

- $\quad$ The energy source (Dispatchable and Non-Dispatchable): in Dispatchable DGs, the generated power is fixed and known in Markov State Models [126,127], whereas in Non-Dispatchable units (e.g., wind and solar) the generated power depends on the availability of the intermittent sources.

Table 4. Reliability assessment techniques of distributed generation (DGs) in islanded mode [126,127].

\begin{tabular}{|c|c|c|c|c|}
\hline Ref. & Technique & DG Type & Generation Model & Load Model \\
\hline$[128,129]$ & Analytical & Dispatchable & - & - \\
\hline [130-132] & Monte Carlo Simulation & $\begin{array}{c}\text { Dispatchable } \\
\text { Non-Dispatchable }\end{array}$ & 3 states Markov Models & Averaging \\
\hline [133] & Monte Carlo Simulation & $\begin{array}{c}\text { Dispatchable } \\
\text { Non-Dispatchable }\end{array}$ & Probabilistic approach & Probabilistic approach \\
\hline [133-135] & Monte Carlo Simulation & $\begin{array}{c}\text { Dispatchable } \\
\text { Non-Dispatchable }\end{array}$ & Hourly profile & Hourly profile \\
\hline [136] & Analytical & $\begin{array}{c}\text { Dispatchable } \\
\text { Non-Dispatchable }\end{array}$ & Levels of a typical day & Levels of a typical day \\
\hline$[132,137,138]$ & Analytical & $\begin{array}{c}\text { Dispatchable } \\
\text { Non-Dispatchable }\end{array}$ & Probabilistic approach & Probabilistic approach \\
\hline [139-142] & Analytical & $\begin{array}{c}\text { Dispatchable } \\
\text { Non-Dispatchable }\end{array}$ & Segment of a year & Segment of a year \\
\hline
\end{tabular}


Table 5. Reliability assessment techniques for DGs in grid-connected mode of operation [126].

\begin{tabular}{ccccc}
\hline Ref. & Technique & System Constraints & Power Flow & Transferred Capacity \\
\hline$[143,144]$ & Analytical & Voltage and load & Yes & Computed \\
\hline$[145]$ & Monte Carlo Simulation & Loading & No & Computed \\
\hline$[146]$ & Analytical + Monte Carlo Simulation & Loading & No & Computed \\
\hline
\end{tabular}

\subsection{Demand Response}

The Federal Energy Regulatory Commission defines Demand Response (DR) as "the changes in electric usage by consumers from their normal consumption behavior in response to new pricing schemes, elevated sense of responsibility, and incentive pricings that are mainly designed to induce lower electricity consumption during high price periods or when system reliability is jeopardized" [147]. In Demand response, consumers are actively involved in grid operations as they can adjust their electricity consumption during peaking hours and may benefit through financial incentives. DR may also provide adequate capacity during the state of contingencies instead of relying on traditional measures such as shedding loads to restore the functionality of the system [126]. In addition to the relevant references highlighted earlier or later in this paper, the pivotal role of Demand Response in smart grids has been thoroughly reviewed in References [148-154] and the classification of demand response programs is depicted in Figure 2.

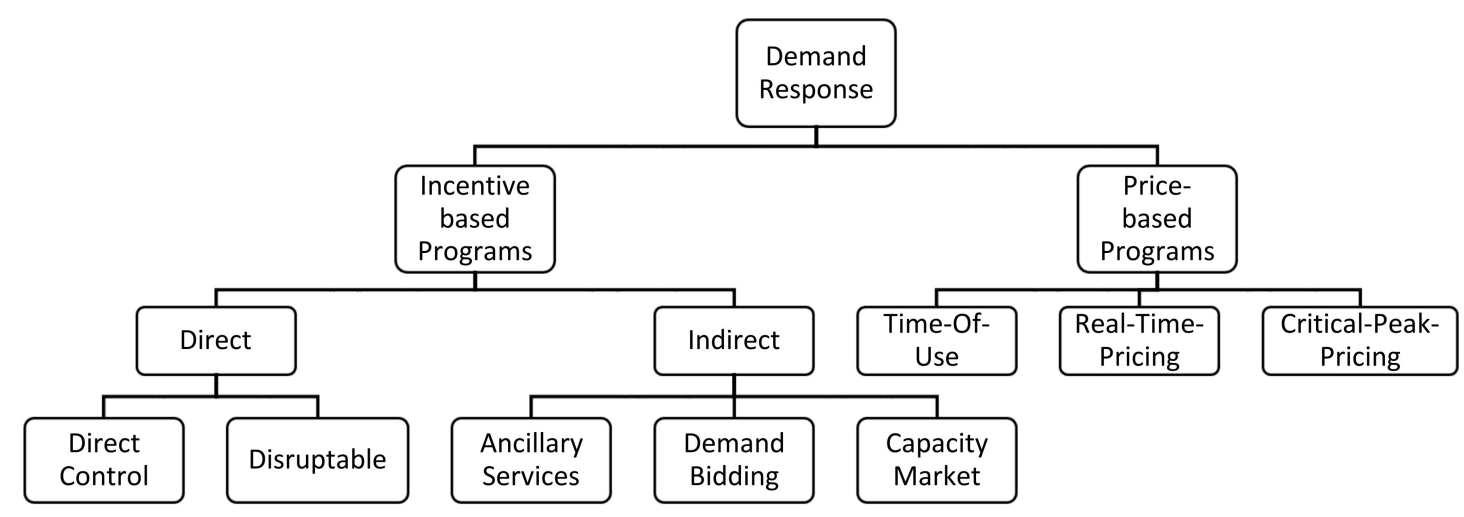

Figure 2. Framework and classification of demand response programs $[73,155]$.

Demand response has a vital role in shaping the future power grid in addition to the storage technologies, distributed generation, and communication infrastructure $[73,153,155]$. In conventional power grids, consumers are effectively passive and have no choice whatsoever to monitor or/and to participate in controlling their adjustable devices intelligently. On the contrary, in smart grids, consumers are more involved in many aspects of the restructured power grid. Demand response can be classified into Price-based programs and Incentive-based programs. In the former, end-users are offered several pricing mechanisms, whereas the latter offers incentives for end-users for performing specific tasks $[73,126,155,156]$. Furthermore, the latter is also broken down into Direct Control Load (DCL) and Indirect Control Load (ICL). The former allows the utility to adjust the energy consumption for the controllable devices with notification beforehand, while the latter is designed for appliances that can be disrupted over a short period to reduce the peak during heavy loading conditions. The following flowchart summarizes the DR programs.

\subsubsection{Reliability of Demand Response}

Although demand response causes load curtailment, it is essential to distinguish the DR actions from the natural interruptions (i.e., partial or complete failure of the components) while carrying out traditional reliability assessments [157]. More often, the former is planned beforehand, whereas the 
latter is unforeseen, and consumers will not be able to take any precautions to alleviate the problem. Moreover, DR is performed on less sensitive loads (i.e., thermostatically controlled devices), thereby such devices may remain energized. The impact of DR on reliability requires additional metrics compared to traditional reliability assessments [126,157]. For further details, the authors of Reference [157] discussed thoroughly different reliability techniques. Table 6 summarizes different reliability techniques that can be used in DR programs.

Table 6. Distinct propositions and techniques for reliability assessment of DRs in the literature [126].

\begin{tabular}{cccccc}
\hline Ref. & Technique & Operating Mode & DR Program & DR Criteria & ICT Impact \\
\hline$[161]$ & Analytical & Grid Connected & Incentivized & Interruption cost minimization & No \\
\hline$[113]$ & SMCS & Grid Connected & Incentivized & Shifting less critical loads & No \\
\hline$[158,162]$ & Analytical SMCS & Grid Connected & Incentivized & $\begin{array}{c}\text { Minimizing interruption } \\
\text { cost/payback incentives }\end{array}$ & Yes \\
\hline [159] & SMCS & Off-grid & TOU & $\begin{array}{c}\text { Conflictive objectives to maximize } \\
\text { the profits of the supplier and to } \\
\text { minimize the payments } \\
\text { of consumers }\end{array}$ & Yes \\
\hline$[160]$ & SMCS & Off-grid & Incentivized & Interruption cost minimization & Yes \\
\hline
\end{tabular}

The available capacity that might exist once the loads are curtailed needs to be precisely allocated and considered during conducting reliability studies. Besides, load profiles over different time horizons are necessary to model the demand in reliability assessment. Furthermore, Sequential Monte Carlo Simulation (SMCS) is frequently used to assess the reliability as in References [113,158-160]. DR programs can be classified into three classes according to the party in-charge as follows:

- Reliability-based (Incentive-based) Programs: in this program, a set of demand curtailment signals are sent to the participants in the form of voluntary requests or mandatory commands.

- Rate-based Programs: the prices are set beforehand over a period. Consumers are obliged to pay higher rates during peaking instants and lower prices during off-peak periods. This program is seen as a Time-of-Use (TOU) structure.

- Demand Reduction Bids: in this program, the participating consumers submit their bids to the demand aggregator or the independent system operator (ISO) offering their available capacity to be curtailed.

\subsubsection{Applications of Demand Response}

Controllable demands or aggregated demand response (DR) may act as a Virtual Energy Storage Systems (VESS). Intelligent management of the power and energy consumption of DR may result in functions similar to those provided by energy storage devices. Furthermore, the smart utilization of the existing assets will provide the ancillary services required at a much lesser cost. For instance, $1.5 \mathrm{~m}$ of aggregated refrigerators with a total capacity of $20 \mathrm{MW}$ would cost $£ 3 \mathrm{~m}$ as compared to the VESS, which costs nearly $£ 20-£ 25 \mathrm{~m},[163-165]$. Furthermore, DR has the potential to reduce the ESS market share by $50 \%$ in 2030 [165].

Frequency regulations services can be provided by proper adjustments to the power consumption of the controllable devices [166-174]. A control algorithm for dynamically controlled refrigerators was proposed in Reference [166] to provide primary frequency control services in Great Britain. The authors of Reference [167] investigated the ability of dynamically controlled loads to maintain grid frequency within a particular range after a sudden loss of generation. The study indicated a significant delay in frequency fall and less reliance on rapidly deployable backup generators. In Reference [168], the authors used aggregated controlled bitumen tanks to provide sufficient reserve capacity for frequency support applications. The model was proved to be more reliable and faster in response compared to a frequency-sensitive generating units. 
The authors of Reference [169] investigated the potential range of average power that can be offered by electric water heaters if adequately controlled for power-balancing applications. The control strategy was achieved by adjusting the setpoint temperature and the drawn hot water. The authors in Reference [170] presented a methodology to support grid frequency and voltage profile by using a controllable load consisting of an electric water heater and electric vehicles. A decentralized controllable protocol was developed to suppress active and reactive power fluctuations of renewables. In addition, Reference [175] proposed aggregated electric vehicles to provide a centralized supplementary frequency regulation through a mediator between the demands and the power system control center considering the charging requirements. The authors in Reference [171] investigated the availability of domestic refrigerators and industrial bitumen tank load to provide frequency response services. A decentralized controller was proposed to adjust load power consumption in proportion to grid frequency. In Reference [172], a two-layer control algorithm for thermostatically controllable loads to effectively participate in fast frequency regulation services due to the scarcity of AGCs in Microgrid that is highly penetrated by RESs has been proposed.

On the other hand, the authors of Reference [173] proposed a collaborative control scheme to improve the stability of islanded Microgrids. Unlike other control schemes, this study deploys all agents in the Microgrid to provide the reserves needed to achieve system stability. The presented algorithm used an MPPT to limit the power output of the solar panels during frequency rise events. In Reference [174], a comprehensive central demand response strategy for frequency regulation support with minimal adjustments to the load was presented. A simulation on the 13-bus IEEE benchmark was carried out to validate the study.

\subsection{Energy Storage Technologies}

Energy Storage Systems (ESSs) are fundamental parts when it comes to renewable energy resources incorporated in smart grids. The variability of such resources can be mitigated by an efficient operation of the ESSs. Energy systems store the excessive energy during off-peak periods and supply it back during peaking hours. Conventional storing technologies can provide numerous applications in power systems in addition to their primary functions, as depicted in Figure 3 [176]. The application of energy storage is not new, yet the technologies require further developments. Similarly, the operational schemes for the energy-storing devices are designed intensively for respective exclusive applications. Their inherent degraded efficiencies and high capital costs are still questionable despite the rapid developments in other fields, owing to the Electric Vehicles (EVs). Therefore, their operation and size need to be carefully optimized. In this respect, the authors of References [177-183] have thoroughly reviewed the role of storage systems in modern smart grids in terms of applications, costs, characteristics, optimal operation, sizing, and hybridization of storage technologies. For instance, the applications may include, but not limited to, energy arbitrage [184-189], peak shaving [190-192], frequency regulation [193-196] and [197], spinning reserves [198], voltage support [199-201], black start capabilities [202], intermittency smoothing [203], congestion mitigation [204], system expansion deferrals [205], multi-agent grid services [206-209], and load-following applications [210]; Tables 7 and 8 highlight the most recent characteristics of storage technologies.

Within the layout of ancillary services, Electric Vehicles (EVs) can be used as an independent energy source. Once the EV is parked, the energy can be retrieved back into the grid (Vehicle to Grid V2G) [211-213]. Fixed or roaming energy storage systems can be deployed to provide sufficient reserve capacity for ancillary services purposes [214-218]. For instance, the authors of Reference [212] have proposed a real-time control strategy for a fleet of EVs to provide ancillary services. The proposed controller has considered the bidirectional charging/discharging efficiency in an extended effect during the implementation of Model Predictive Control (MPC). The simulation that has been carried out has revealed a significant improvement in battery lifetime extension, tracking error, and regulation capacity. A planning framework for a virtual investor that aims to provide ancillary services to a wholesale market has been proposed in Reference [213]. Two alternatives have been presented for 
the investor. The former has used a dedicated battery to achieve the objective, whereas the latter has deployed aggregated EVS to achieve the same task. The objective of the proposed optimization model is to maximize the long-term payoffs for the investor by providing an optimized daily bidding strategy. The proposed study has used an economic measure (i.e., present worth) to compare the alternatives. A sensitivity analysis has been carried out to investigate the impact of planning and operation variables on the feasibility of the two alternatives.

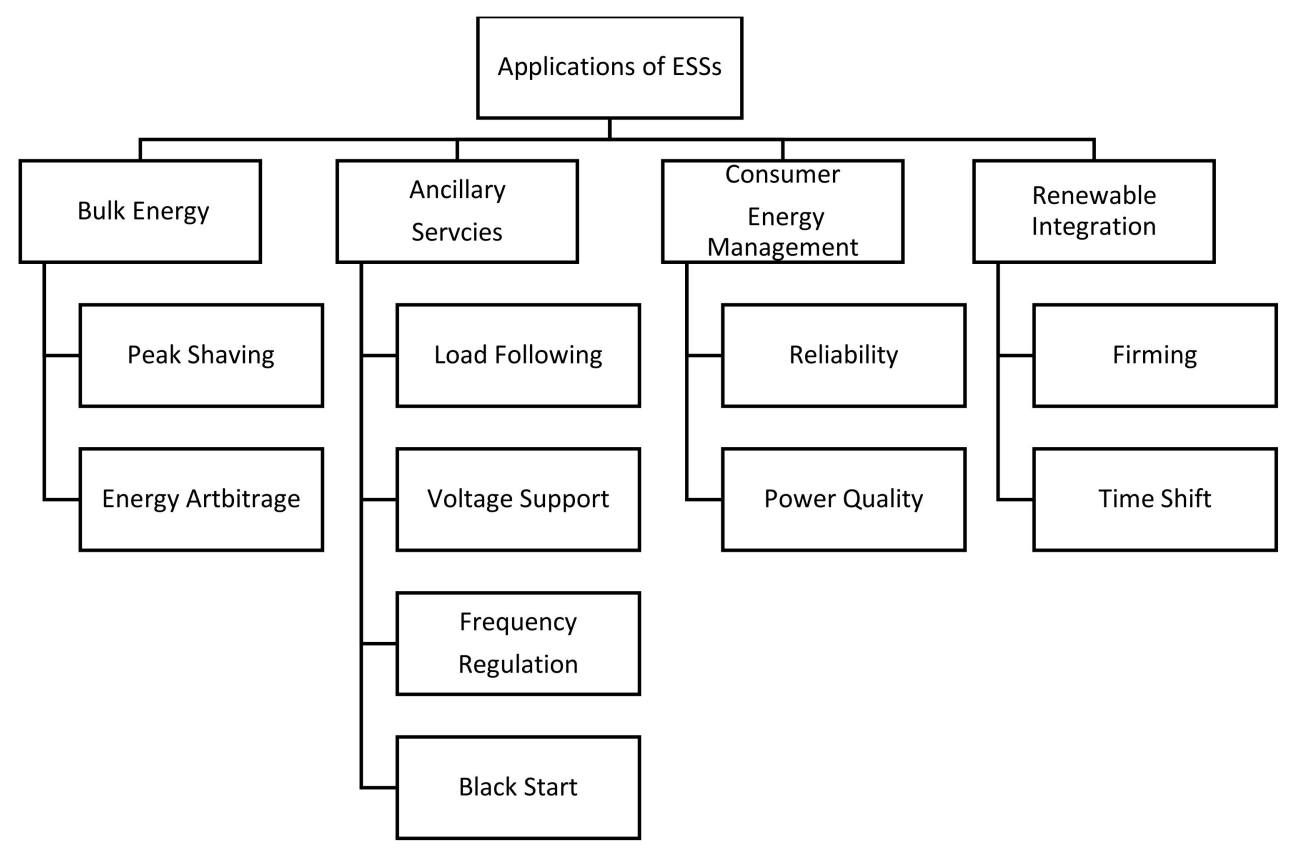

Figure 3. Multifaced applications of energy storage systems in smart grids [176,219].

Table 7. Technical characteristics of energy storage technologies [220,221].

\begin{tabular}{|c|c|c|c|c|c|c|c|}
\hline \multirow[t]{2}{*}{ Energy S. Technology } & \multirow{2}{*}{$\begin{array}{c}\text { Energy Density } \\
\mathrm{Wh} / \mathrm{kg}\end{array}$} & \multirow{2}{*}{$\begin{array}{c}\text { Power Density } \\
\mathrm{W} / \mathrm{kg}\end{array}$} & \multirow[t]{2}{*}{ Discharge Time } & \multirow{2}{*}{$\begin{array}{c}\text { Lifetime } \\
\text { (Year) }\end{array}$} & \multicolumn{2}{|c|}{ Capital Cost } & \multirow{2}{*}{$\begin{array}{c}\text { Technological } \\
\text { Maturity }\end{array}$} \\
\hline & & & & & $\$ / K W$ & $\$ / K W h$ & \\
\hline \multicolumn{8}{|c|}{ Mechanical Energy Storage } \\
\hline PHES & $0.5-1.5$ & - & $1-24 \mathrm{~h}+$ & $40-60$ & 600-2000 & 5-100 & Matured \\
\hline CAES & $30-60$ & $(0.5-2.0)$ & $1-24 \mathrm{~h}+$ & $20-40$ & $400-800$ & $2-50$ & Developed \\
\hline Flywheel & $10-30$ & $400-1500$ & Millisec-15 min & 15 & $50-300$ & 500-1000 & Commercial \\
\hline \multicolumn{8}{|c|}{ Electrochemical Energy Storage } \\
\hline Lead Acid Battery & $30-50$ & $75-300$ & Sec-hrs & 5-15 & $200-300$ & $120-150$ & Commercial \\
\hline NiCd Battery & $50-75$ & $150-300$ & Sec-hrs & $10-20$ & $500-1500$ & $800-1500$ & Commercial \\
\hline Sodium Sulfur (NaS)Battery & $150-240$ & $150-230$ & Sec-hrs & $10-15$ & $1000-3000$ & $300-500$ & Commercial \\
\hline Lithium Battery (Li-ion) & $75-250$ & $150-315$ & Mins-hrs & 5-15 & $1200-4000$ & $300-1300$ & Demonstration \\
\hline VRFB & $10-30$ & - & Sec-10 h & $5-10$ & $600-1500$ & $50-1000$ & Demonstration \\
\hline \multicolumn{8}{|c|}{ Electrical Energy Storage } \\
\hline SuperCapacitor & $2.5-15$ & $500-1300$ & Millisec-60 Min & $20+$ & $100-300$ & $300-10,000$ & Developed \\
\hline SMES & $0.5-5$ & $500-2000$ & Millisecs-sec & $20+$ & $200-300$ & $1000-10,000$ & Demonstration \\
\hline \multicolumn{8}{|c|}{ Chemical Energy Storage } \\
\hline Hydrogen Fuel Cells & $800-10,000$ & $500+$ & Sec-24 h+ & 5-15 & - & $6000-20,000$ & Developing \\
\hline SNG & 10,000 & $(0.2-2)$ & $1-24 \mathrm{~h}+$ & $10-30$ & - & - & Developing \\
\hline \multicolumn{8}{|c|}{ Thermal Energy Storage } \\
\hline CSP & -43.05 & - & Mins-hrs & 30 & - & $3500-7000$ & Developing \\
\hline
\end{tabular}


Table 8. Associative characteristics of energy storage technologies $[220,221]$.

\begin{tabular}{|c|c|c|c|c|c|c|c|}
\hline Energy S. Technology & Power Rating & $\begin{array}{c}\text { Storage } \\
\text { Duration }\end{array}$ & $\begin{array}{l}\text { Self-Discharge } \\
\text { per Day }\end{array}$ & $\begin{array}{l}\text { Cycle Life } \\
\text { (cycles) }\end{array}$ & $\begin{array}{c}\text { Round trip } \\
\text { Efficiency (\%) }\end{array}$ & Response Time & Class \\
\hline \multicolumn{8}{|c|}{ Mechanical Energy Storage } \\
\hline PHES & 100-5000 MW & Hrs-Mons & Very small & - & $65-87 \%$ & $\mathrm{~L}-2 \min$ & Long term \\
\hline CAES & 5-300 MW & Hrs-Mons & Small & - & $50-89 \%$ & $1-2 \mathrm{~min}$ & Long term \\
\hline Flywheel & $0-250 \mathrm{~kW}$ & Sec-Mins & $100 \%$ & - & $85-95 \%$ & $1-2 \mathrm{~min}$ & Short term \\
\hline \multicolumn{8}{|c|}{ Electrochemical Energy Storage } \\
\hline $\begin{array}{l}\text { Lead Acid } \\
\text { Battery }\end{array}$ & 0-20 MW & Mins-days & $0.1-0.3 \%$ & $500-1000$ & $75-80 \%$ & Seconds & Long term \\
\hline NiCd Battery & $0-40 \mathrm{MW}$ & Mins-days & $0.2-0.6 \%$ & $2000-2500$ & $85-90 \%$ & Seconds & Long term \\
\hline Sodium Sulfur (NaS) battery & $50 \mathrm{~kW}-8 \mathrm{MW}$ & Sec-Hrs & $20 \%$ & 2500 & $80-90 \%$ & Seconds & Short term \\
\hline Lithium Battery (Li-ion) & $0-100 \mathrm{~kW}$ & Mins-days & $0.1-0.3 \%$ & $1000-10,000+$ & $85-90 \%$ & Seconds & Long term \\
\hline VRFB & $30 \mathrm{~kW}-3 \mathrm{MW}$ & Hrs-months & Small & $12,000+$ & $85-90 \%$ & Seconds & Long term \\
\hline \multicolumn{8}{|c|}{ Electrical Energy Storage Systems } \\
\hline $\begin{array}{c}\text { Double Layer } \\
\text { Capacitor/super Capacitor }\end{array}$ & $0-300 \mathrm{~kW}$ & Sec-hrs & $20-40 \%$ & $100,000+$ & $90-95 \%$ & Milliseconds & Short term \\
\hline SMES & $100 \mathrm{~kW}-10 \mathrm{MW}$ & Sec-hrs & $10-15 \%$ & $100,000+$ & $95-98 \%$ & Millisecond & Short term \\
\hline \multicolumn{8}{|c|}{ Chemical Energy Storage Systems } \\
\hline Hydrogen Fuel cell & $0-50 \mathrm{MW}$ & Hrs-months & Nearly 0 & $100+$ & $20-50 \%$ & Sec-Mins & Long term \\
\hline \multicolumn{8}{|c|}{ Thermal Energy Storage Systems } \\
\hline CSP & $10 \mathrm{~kW}-20 \mathrm{MW}$ & - & $1 \%$ & - & $<60 \%$ & $10 \mathrm{~min}$ & Long term \\
\hline
\end{tabular}

On the other hand, the authors of Reference [214] proposed a Virtual Energy Storage System (VESS) that consists of controllable demands and Flywheel Storage System (FSS) to provide power system ancillary services. Feasibility studies were carried out to validate the benefits of deploying such protocols over conventional measures. A hybrid ultra-capacitor and battery storage systems were proposed in Reference [215] to provide large scale regulation services. The proposed scheme aims to mitigate the abusive utilization of the battery and to increase the profitability of regulation services. Moreover, Reference [216] presented a vanadium-redox flow battery-based energy device model to provide multi-ancillary services focusing on peak-shaving application and frequency support. A cooperative dynamic energy level balancing based on consensus control among distributed energy storage devices offering frequency regulation capabilities in a droop-controlled Microgrid was investigated in Reference [217].

Furthermore, the authors of Reference [222] presented a study that assesses the financial performance of a battery energy storage system (BESS) to provide market-based frequency regulation services. The potential impact on profitability was also highlighted and evaluated. On the other hand, the replacement of bulky conventional generators by renewables may result in an inertial mass reduction, which jeopardizes grid stability. Therefore, the authors of Reference [193] have proposed a coordinated control scheme to effectively operate a hybrid system that is composed of ultra-capacitor and batteries for ancillary services purposes in the electricity market.

\section{Data Management}

\subsection{Energy Data Management in Smart Grids}

One of the main challenges toward the transformation into a functional smart grid is the scarcity of resources [223]. A smart city incorporates engineering solutions and informatics capabilities to effectively run a reliable network. It encompasses a wide range of intelligent services such as smart grids, smart transportation, smart education, smart waste management, and smart communication. Among these, the smart grid forms the backbone of the hierarchal structure of the smart city because it supplies sustainable energy to all other parts to guarantee a successful integration. Smart grids should comprise intelligent data systems in order to function appropriately. Capturing and processing such a massive amount of information needs to be carefully addressed. For instance, the References [224-235] are dedicated to investigating the progress in the field of big energy data management by enumerating 
different studies that have been reported to cover several data management aspects that involve data collection, data preprocessing, data integration, data analytics, data storage, visualizing the data, and decision-making.

The traditional grid heavily relies on primitive data that can be collected through limited points within the network, such as demand data, voltage data, and current data. On the contrary, the smart grid captures real-time data through enormous data points within the grid where the process can be referred to as big energy data. It may include smart meter data, dispersed sensors data, weather forecast data, load profile patterns, and may even carry out online operations for a wide range of power system applications. However, once the data are collected, proper analyses are performed to assist decision-makers in making their right decisions. The collected online data may also assist consumers to adjust their electricity consumption during peaking periods. They also help utilities in determining the faulty networks and restore the grid to regular operation. However, the expansion in advanced infrastructure brings new challenges from the data standpoint of view (e.g., data security, data privacy, cost of data storage, and retrieval).

\subsubsection{Data Collection}

The flow of data management in smart grids is sequentially organized, as depicted in Figure 4. However, the data collection phase is the first step in the data management process, where the information is collected from the data centers [236]. The ultimate source of data is the so-called advanced metering infrastructure (AMI) that retrieves the information from end-users' premises. The AMI measures and collects the data every 10-15 min. The data are prone to an escalation in size, depending on the population of a given location. For instance, in Australia, Sydney has a population of nearly 4,000,000, where the last report from the Australian Bureau of Statistics indicates that there are a total of 1850 dwellings are located in Greater Sydney [237]. Such a large number of dwellings emphasizes that there are approximately 267,228,432 messages sent to the control center each day. There are, however, several data loggers that can transmit data in smart grids such as sensors data, power metrics data, mobile terminals, metadata, control devices, historical data, and reliability data [238]. Geographic information systems (GIS) may also contribute to smart grids by providing a piece of valuable information that can be utilized to perform specific tasks such as identifying the proper PV farm to be installed, visualization of generation, and distribution facilities [239-241].

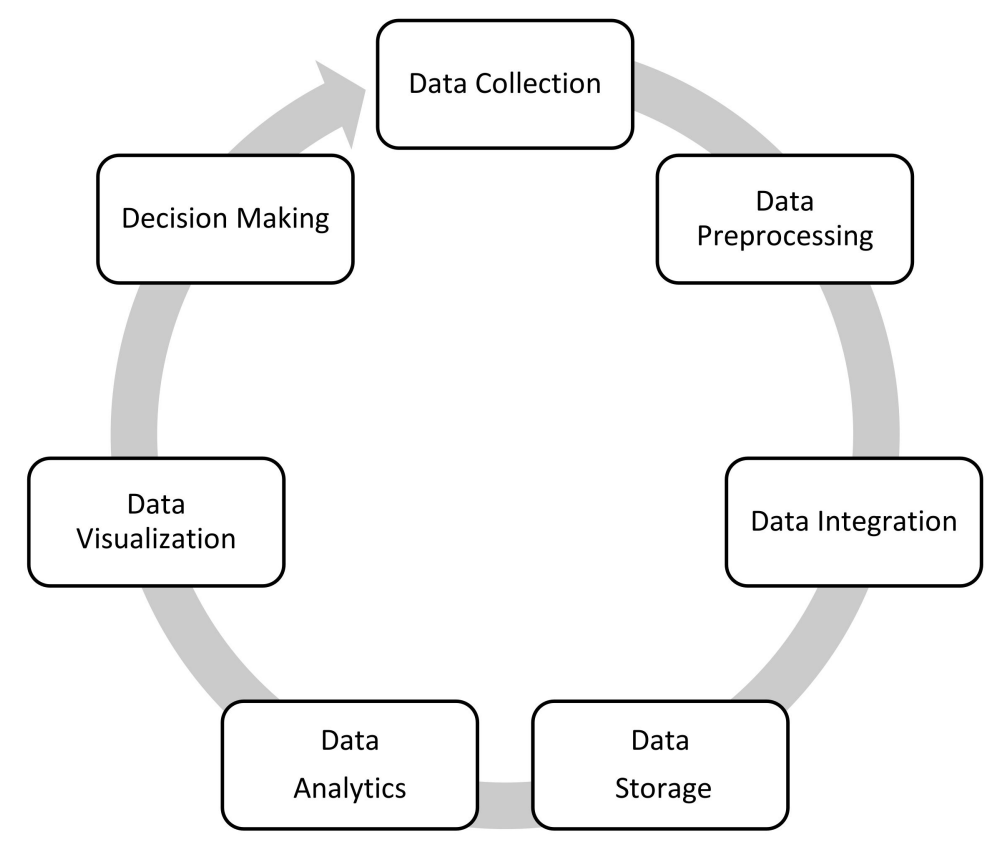

Figure 4. Flow of data in smart grids. 
There has been continuous progress in this area to address some challenges, such as standards, security, privacy, reliability, and scalability [223]. For instance, the authors of References [242,243] investigated the data collection attribute from the security and privacy point of view. On the other hand, the authors of References $[244,245]$ investigated the data collection in a nonhierarchical network. The proposed studies developed a lightweight message authentication framework for smart grid data communication, considering privacy [246]. Other studies were devoted to investigating reducing storage when establishing multiple sessions with source devices/sensors [247]. The authors in Reference [248] proposed a smart meter data reporting strategy based on three novel data collection mechanisms to optimize the performance of the communication network and the performance of TCP-based communication in IEEE 802.11s mesh AMI networks.

\subsubsection{Data Preprocessing}

In this phase, the data collected undergo several processes before performing any task of analysis. However, the data acquired might be incomplete, inaccurate, and need to be filtered out where this process is known as data cleansing [249]. The data-cleansing phase comprises five steps. That is, once the erroneous data are received, they are defined, identified, corrected, documented, and modified to avoid future faults [250]. For instance, in smart grids, data cleansing helps in forecasting the generation from the PV system to decide the proper dynamic tariff rate [251,252].

The acquired data may even suffer from redundancy and repetition, which require more storage capacity and add more cost. Hence, the redundant data need to be identified and eliminated [253-255]. The authors of Reference [256] presumed that the data collected from smart grids facilities are equivalent to the data generated from media platforms. As reported above, data preprocessing may involve data cleaning, data aggregation, redundancy, repetition, and elimination [257-260]. In particular, the authors of Reference [261] discussed the data aggregation aspects where most of which were devoted to addressing privacy preservation. However, data aggregation helps in keeping them anonymous to preserve privacy.

\subsubsection{Data Integration}

Before the data get assimilated once originated from scattered data points, the data collected are not uniform and need to be appropriately integrated before the analysis $[223,262]$. For example, the load profile data and weather condition data are integrated to help utilities optimize and schedule their power production in accordance to the demands considering uncertainties [262-264].

\subsubsection{Data Storage}

In the data storage phase, the data get stored, located, and can be accessed at any instant of time [224]. In traditional grids, the load data profiles are stored for load forecasting purposes, hence they do not require excessive data storage capabilities. On the contrary, in smart grids, a wide range of data needs to be allocated and stored. The speed of processing the input/output information of the data storage is crucial due to the online operations that need to be performed [265]. Smart grids collect a massive amount of diversified data from various spots. The ability to access the stored data needs to be fast enough for real-time operations. There are several approaches reported in the literature for effective data storage mechanisms. For instance, the authors of Reference [266] proposed using the Simplified Mandatory Access Control Kernel (SMACK)-based framework, which combines Kappa and Lambda for data storage in Microgrids, while [267] utilized a graph storage approach to effectively store collected data in smart grids. The authors suggested an automatic migration of a database from the Resource Description Framework (RDF) to a graph storage engine. The schematics representation of the overall data flow is presented in Figure 4. 


\subsubsection{Data Mining and Data Analytics}

In smart grids, a massive amount of data is regularly gathered. Several applications are then performed on the data gathered, such as end-users' behavior analysis, state analysis, and fault analysis. The analyses that need to be carried out are classified according to the response time required while processing the data. The first category, which does not require high response time, may include nonurgent operations such as long load forecasting [268] and customer analysis. Faults analysis and smart metering data are designated among those applications that need to be analyzed as quickly as possible. For example, the authors of Reference [224] proposed the use of a machine-learning algorithm to process local data to save network bandwidths, reduce time delays. Furthermore, the proposed study deployed a central processor to act as a mediator between local processors. Such a mixing approach contributed to overall cost reduction.

\subsubsection{Data Visualization}

Data visualization provides a visual representation to help decision-makers for better analysis assimilation $[269,270]$. The insights provided by data visualization may contain graphs that are more efficient to understand than digesting only numerical data. It provides visual patterns that help in recognizing the sources of concerns and sources of opportunities. There are several visualization tools (e.g., 2D and 3D Vis tools) available in the market that can be used by both consumers and utilities to visualize the end-user power consumption, generation of renewable-based sources, and power quality data. Moreover, GIS software such as ArcGIS, QGIS, MapInfo, and Maptitude are valuable alternatives for visualizing smart grid data on the maps [270].

\subsubsection{Online Decision-Making}

Smart grids allow a real-time and automated decision-making process where such features are unlikely seen in traditional grids [271]. Important decisions can be taken, such as real-time pricing mechanisms, the capability of providing on-demand renewable generation, and estimating capacity constraints [271,272]. The ability to provide real-time analysis and decisions is impacted on reliability improvement in smart grids and thereby increasing end-user's confidence in the technology. Based on real-time analysis, it is easier to visualize the faulty sections in the smart grids, isolate them, and take the proper corrective measure to mitigate such issues [273].

\subsubsection{Data Management Challenges in Smart Grids}

The data gathered from various spots support the functionality of smart grids and helps to attain intelligent decisions once needed. The data collected supports consumers and utilities to manage their energy effectively, helps both participants to optimize their usage or production, and allows an interactive mode among different participants. However, such massive data bring numerous challenges in terms of volumes, reliability, scalability, as well as data security and privacy. Storing such massive data requires enormous storage capacity. However, the current infrastructure may lack the skilled workforce to manage such amount of data. Therefore, active participation from end-users to deal with smart metering data is mandatory to ensure maximum utilization. On the other hand, data reliability and scalability are essential attributes and required to place confidence in the data for a trustworthy decision-making process.

\subsection{Cyber Security of Smart Grids}

Due to the necessity of data security issues, we devoted this sub-section to highlight the complexity of the widespread problems in cybersecurity. The advanced automation and communication capabilities in smart grids expose the entire system to cyber threats. Although the integration of smart grids empowers electric utilities and end-users and enhances the reliability and availability of the service with the ability to monitor and manage the behavior of the demands continually, it brings 
various security constraints and vulnerabilities [274,275]. Antagonists may illegally and arbitrarily disrupt the system dynamics or induce a secondary perturbation if no proper security measures are taken [276]. Cybersecurity issues, threats, vulnerabilities, and countermeasures have been extensively investigated in the literature, particularly during the past decade due to the rapid advancements in automation [277-289]. However, within the analysis framework, it is very critical to find adequate mathematical models that describe the cyber attacks. However, cyber attacks can be classified into Denial of Service (DoS) attacks, reply attacks, and deception attacks whose models are summarized in Table 9.

Table 9. Mathematical models of cyber attacks $[276,290]$.

\begin{tabular}{cc}
\hline Type of Attack & Mathematical Model \\
\hline DoS attacks & $\overline{y_{k}} \in \phi:$ refers to data failure, $\overline{y_{k}}$ and $y_{k}$ are the received data and the measured data, respectively. \\
\hline Reply attacks & $\overline{y_{k}} \in Y:$ refers to the previous information. \\
\hline Deception attacks & $\overline{y_{k}}=y_{k}^{a}+y_{k}:$ where $y_{k}^{a}$ indicates to the erroneous data injected by intruders. \\
\hline
\end{tabular}

DoS refers to the attempts that are carried out by adversaries to disrupt system resources and make them unavailable. Up to date, there are few models reported that can quantify the performance degradation, among which the Queuing models [291-293], Bernoulli models [294], and Markov models [295]. In Queuing models, attacks are transformed into a timely delayed system where the traditional analysis can then be performed to investigate the stability [296-298]. For example, the authors of Reference [292] proposed a round-trip-based predictive control protocol to neutralize the adverse impact that results from weak DoS attacks. On the other hand, in Replay attacks, antagonists maliciously contaminate the valid data. Such attacks are not easily detectable since they pass the examination of cryptographic keys [276]. Further beyond, attackers may create channels between two terminals acting as a mediator, and they lunch repetitive messages [299]. In Deception attacks, adversaries manipulate the integrity of the transmitted data [300,301]. The objective of cyber attacks is to destroy the performance of the system and immobilize the network temporarily or permanently. The impact of cyber threats is not only limited to the service provided but also extended to affect the economy [276]. Therefore, attack detection techniques are vitally crucial in cyber-physical systems especially in power system applications. Bad data detectors are incorporated to detect the deviated estimates and may provide alarming according to the tolerance that is set beforehand [302-305]. However, there are two defense approaches against cyber attacks, the former protects the essential components before the attack takes place, whereas the latter identifies the contaminated data that were injected by adversaries afterward [306]. For example, sensitive information can be placed inside normal readings using a wavelet-based steganography technique [307]. In the second approach, the incorrect data are isolated and removed once the attack is detected. So far, there are four detection schemes in cyber system: (1) Bayesian detection [308-310]; (2) weighted least square (WLS) [311-314]; (3) Kalman filters-basedx2-detector [315,316]; and (4) quasi-FDI (fault detection and isolation) techniques [317,318].

Within the framework of smart grids, it is very imperative to realize the interaction between the physical system and the cyber system. The Supervisory Control and Data Acquisition (SCADA) system, which controls the electrical grid, can be regarded as the primary target for attackers [319]. For instance, the authors of Reference [320] imputed the cyber-vulnerabilities to the data being exchanged by the Wide Area Network (WANs) between various entities. SCADA incorporates various sophisticated units such as AMI, DER, and Distribution Automation (DA) in the distribution system, which increase the level of damages once attacks take place. However, the systems that can be affected by attacks may include SCADA, Programmable Logic Controller (PLCs), and nuclear facilities [321,322]. An assessment layout to evaluate the potential vulnerabilities in the SCADA system was proposed in Reference [323]. The authors proposed a meantime-to-compromise as an index to quantify the vulnerabilities. In addition, the high-level penetration of AMI in smart grids brings more challenges in terms of data security. However, the forms of cyber attacks that may target the AMI units, such as 
leakage of the customer information, false data injection, and energy theft, have been identified in References [324-327]. However, the common detection techniques that can be adopted in smart grids are briefly summarized in Table 10.

Table 10. Detection techniques in smart grids [319].

\begin{tabular}{ccc}
\hline Range of Protection & Domain-Based & Detection System \\
\hline SCADA & Networked & {$[328-330]$} \\
\cline { 2 - 3 } Substations & Host & {$[331]$} \\
\cline { 2 - 3 } & Networked & {$[332]$} \\
\cline { 2 - 3 } & Integrated & {$[333-335]$} \\
\hline Wide area monitoring (WAM) & Host & {$[274,336]$} \\
\hline GPS (PMU) & Host & {$[337]$} \\
\hline Distribution system & Host & {$[338]$} \\
\hline AMI & Host & {$[339-342]$} \\
\hline
\end{tabular}

Intruders may access medium control layers and inject false signals or malware that may lead to a complete failure of the entire network. Therefore, the data need to be encrypted to avoid future threats. For instance, during June of 2017, a catastrophic and unprecedented cyber attack took place against the Ukrainian power system, causing a six hours blackout [343]. This incident was considered a milestone in cybersecurity because it was the first major attack that caused a substantial collapse affecting 80,000 people. Two types of malware were cultivated in the facilities. The perpetrators flooded the company's call center with calls to make matters worse and prevent the consumers from reporting their outages. However, the severity of the attack raises new concerns and promotes calls for serious countermeasures to avoid cyber attack severe issues.

\section{Pricing Mechanisms in Smart Grids}

The earliest traditional power grid started as a unidirectional power flow that permits the electricity flow from the generation to distribution centers. The typical structure of the conventional power grid is vertically integrated, where a single entity owns, operates, and controls the generation, transmission, and distribution. Regulated monopolistic utilities are obliged to serve certain regions with a predefined pricing rate [344]. The utilities are allowed to set the prices that recover the operating cost plus "normal" profits where a reviewing process to the prices takes place to mitigate profits reduction [345]. Critics, however, argue that such a policy lacks appropriate pricing mechanisms for effective pricing control and promotes inefficiency, monopoly. They also added that this model had run its course, and the costs of the mistakes that utilities make should not be passed into consumers. Public utilities very often are close to governments where politics may intervene and side with an entity against another [346].

However, the rapid growth in demands, the pressure exerted by critiques led to restructuring the current electricity market. The resulted restructured (Deregulated) market induced the following entities: GENCOs (generating utilities), TRANSCOs (transmission utilities), DISCOs (distribution utilities), RESCOs (Retailers), and ISOs (independent system operators) [347]. International Energy Agency (IEA) indicates that restructuring electricity markets breaks the monopolistic approach exercised by firms and encourages competition among participants. The electric utility has undergone several reforms to lower entry barriers in electricity markets, increase the reliance on market-based output prices, and allow consumers a choice of power suppliers [348]. Such reforms shift the vertically integrated structure toward an open competition in the market, modifying the traditional regulatory regime that somehow protected utilities from the risk effects in terms of cost and demand variations [349]. From the government's perspective, deregulation brings capitals and encourages competitors to diversify their resources. If companies were granted the opportunity to compete for the provision of electricity freely, the efficiency due to such reforms would be impacted by the consumers. In a perfectly competitive market, when all participants compete as 'price takers' (i.e., no big company affects the prices), 
the most efficient generators would make more profits [350]. Once the market-clearing price is defined, efficient generators are always infra-marginal producers. In a deregulated market, renewable-based generators may bid exactly zero marginal cost since there is no operating cost involved [351]. One might observe why perfect competition encourages efficient electricity production.

\subsection{Dynamic Pricing Mechanisms}

In contrary to the conventional grids where the demand is relatively a passive participant, demands in smart grids are more involved in various applications. Electric Power Research Institute (EPRI) introduced demand Side management (DSM) in the 1980s. DSM is a global term that may include various activities ranging from load consumption management to improving energy efficiency [352]. DSM can be implemented through energy efficiency or demand response (DR). The dynamic pricing framework is designed to provide economic incentives for consumers to participate in demand management by means of "the participation of demands". The smart grid infrastructure allows the interactive mode that takes place between the consumers and the utility to accomplish such tasks. However, several dynamic pricing modalities have been proposed for demand response such as Time-of-Use (TOU), Critical Peak Pricing (CPP), Real-Time Pricing (RTP), and Day-Ahead Pricing (DAP) [353]. For instance, the articles [354-359] have adopted the TOU as a price modality, whereas the References [360-370] have used the RTP scheme. Furthermore, CPP modality can be efficiently utilized, as reported in References [371-377], while the authors of References [378-383] have proposed a DAP as a pricing modality in a competitive electricity market. However, the complexity and cost issues may constitute the main barriers toward the expansion in adopting different pricing frameworks as a day-to-day tool in the existing grid [384,385].

The objective of demand response programs is to flatten the load pattern either by consumption reduction during peaking hours or by shifting part of the loads to off-peak periods. Demand response programs can be classified into two broader categories, as depicted in Figure 5, that is, dispatchable and non-dispatchable price-driven programs. The ability for a utility to control the load during peaking hours is known as a dispatchable program. The price-driven programs (i.e., non-dispatchable) are price-sensitive programs that provide different pricing options (Dynamic Pricing Schemes) to control the demand [386-388].

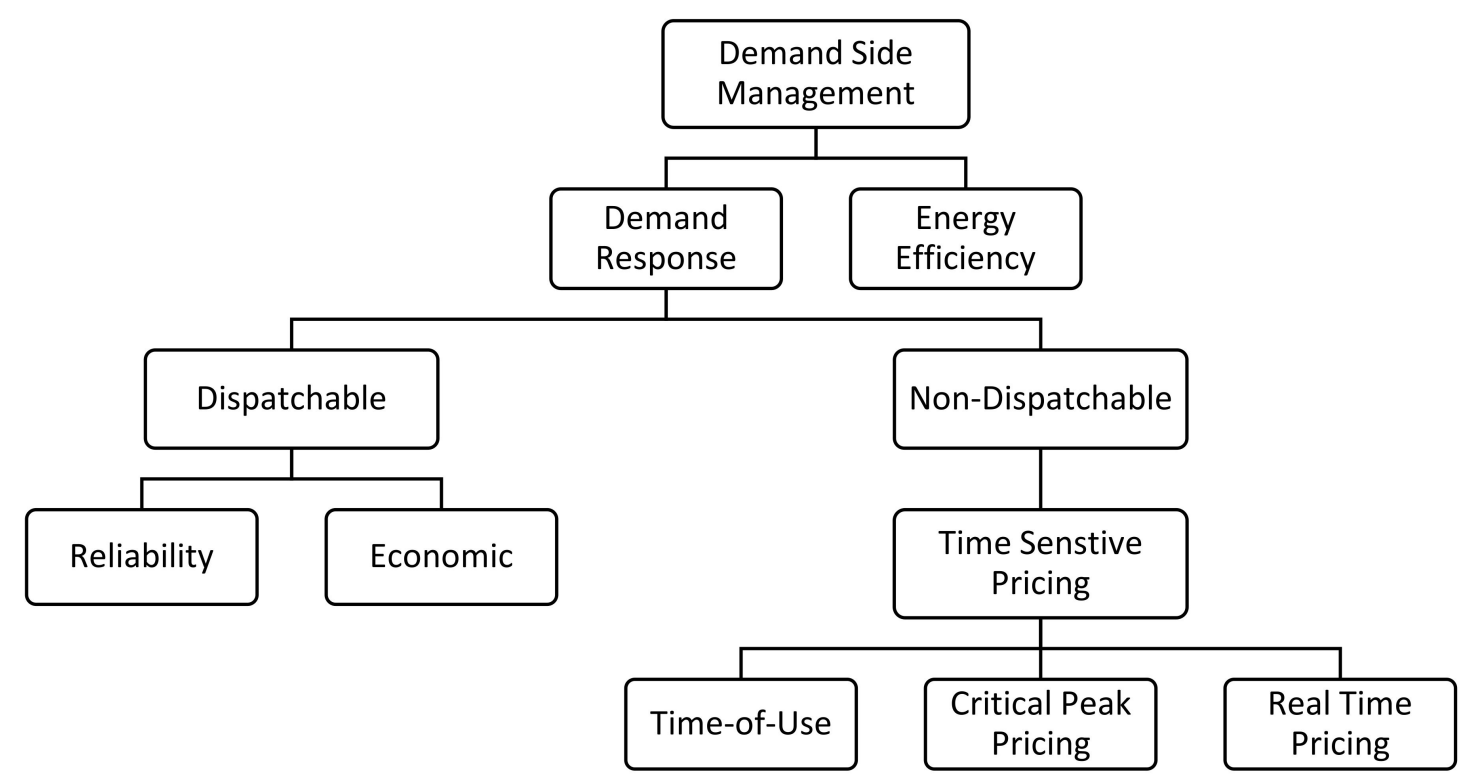

Figure 5. Classification of demand-side management techniques. 


\subsection{Time-of-Use}

In the time-of-use (TOU) approach, a set of different tariffs for different instants of time daily or seasonally is predefined beforehand for a given tariff cycle. TOU is an attempt provided by utilities to alleviate the surge in demands during peaking hours by enforcing a tariff structure that charges higher rates for energy consumption during peaking periods [389]. Time-of-Use tariffs are more often used in areas where consumers have been subjected to a flat rate. Ideally, such a pricing scheme should shift the demand from peak hours to off-peak periods. Although the TOU pricing approach suffers from several challenges, it remains a preferred modality for utilities due to its simplicity. Consumers still tend to prefer such a pricing scheme over other approaches due to the fact that: (i) consumers are used to the fixed tariffs and they might feel hesitant to adhere to frequently changing rates (ii) end-users might not feel comfortable with the variability of Real-Time Pricing [390].

TOU remains one of the most important pricing schemes utilized in DR programs. Naturally, the TOU is a static time-dependent pricing scheme. Although the cost of implementing such pricing approaches is relatively low, difficulties may arise when it comes to real implementation in the existing distribution system. The existing infrastructure lacks the facilities to provide real-time data of consumers' behavior. Therefore, the attempts to replace the current conventional meters with smart meters would significantly impact the expansion of such a pricing policy. Moreover, there are uncertainties involved when it comes to the design of TOU policy due to the constant volatility of generation and demand [355]. Furthermore, different jurisdictions apply different market structures; therefore, they require different TOU policies according to their needs. For instance, the inclusion of space heaters is needed when designing a TOU mechanism in certain territories, whereas, in some places, such a factor is not required depending on the climatic conditions. The presence of DER also needs to be considered when designing an effective TOU scheme.

Given the above, there are several attempts reported in the literature to overcome the challenges usually encountered when applying TOU policy. Table 11 summarizes the challenges and the recent developments of the TOU approach.

Table 11. Recent advances in time-of-use (TOU) modality.

\begin{tabular}{ccl}
\hline Ref. & \multicolumn{1}{c}{ Year } & \multicolumn{1}{c}{ Aim } \\
\hline$[356,391]$ & Jan 2019, May 2013 & $\begin{array}{l}\text { A game-theoretic approach has been proposed to design an optimal } \\
\text { TOU pricing by designing utility functions to reach a Nash equilibrium. }\end{array}$ \\
\hline [357] & August 2012 & $\begin{array}{l}\text { The authors proposed variation inequality models to design an optimal } \\
\text { TOU pricing policy under different market structures. The proposed } \\
\text { study considered the variations in social welfare under different } \\
\text { market schemes. }\end{array}$ \\
\hline$[358,359]$ & May 2018, 2013 & $\begin{array}{l}\text { The authors have investigated the impact of the existence of DER on the } \\
\text { TOU tariffs. }\end{array}$ \\
\hline [392] & December 2013 & $\begin{array}{l}\text { The authors used a stochastic optimization approach and quadratic } \\
\text { programming to design an optimal TOU price, considering the } \\
\text { uncertainties in demand/Generation. }\end{array}$ \\
\hline
\end{tabular}

\subsection{Real-Time Pricing Method}

The Real-Time Pricing (RTP) principle was proposed in early 1982 [360]. It has been widely recognized as one of the promising approaches that maximize the social welfare between consumers and service providers. RTP is a dynamic pricing approach that reflects the spot price of the wholesale market [63]. Electricity (i.e., Energy) is a commodity that can be transacted through biddings and offers. The transactions are settled and cleared by the system operator or market operator through the market clearing process. Once the price is cleared, a price signal is sent to market participants according to the market timeframe (i.e., a day ahead, an hour ahead). In contrary to the TOU pricing policy that follows a pricing scheme by blocks over a predefined cycle, RTP frequently responds to the spot market, and hence it is constantly changing. In a distribution network, a retailer may reveal 
the price a day ahead or on an hourly basis so the end-users can adjust their energy consumption accordingly [361-366].

However, the challenges that may arise when implementing this scheme need to be considered. Among these, a win-to-win case for both consumers and electricity providers needs to be taken care of when designing the framework. Moreover, consumers' load profiles and comfort need to be considered. The availability of consumers to take corrective actions once the price signal is received is not guaranteed and, thereby, consumers might be heavily charged during their absence. However, automated load management capabilities may lessen such adverse impacts to some extent. Furthermore, applying such a pricing policy requires advanced infrastructure and intelligent metering technologies where the high penetration of intelligence increases the exposure to cyber threats. The following Table 12 highlights some of the recent developments in the RTP structure.

\subsection{Critical Peak Pricing}

Several obstacles prevent the expansion of adapting TOU pricing schemes and RTP. The former lacks the incentives that may further reduce the peak demand during heavily loading conditions, while the latter is rather complex when it comes to implementation [393]. However, the shortcomings usually encountered in the TOU and RTP mechanisms, along with the fast-evolving infrastructure, have promoted more interest in peak reduction by utilizing dynamic rates. In a Critical Peak Pricing (CPP) mechanism, a penalty is imposed during the operation within the peaking periods that are known beforehand [371]. CPP pricing policy augments a TOU pricing framework with a dispatchable price (i.e., penalized rate) whenever the system is heavily loaded [393]. Although the CPP policy is relatively less dynamic, it is considered a successful approach in reducing demand peaks. CPP pricing structure is a typical TOU policy with the addition of critical events that are adjusted by the utilities due to system constraints [63]. Such critical events are usually announced a day ahead; thereby, the CPP does not precisely reflect the prices of the wholesale market. Furthermore, the utilities should carefully optimize the new tariffs to make profits even though the demands are expected to be curtailed. For instance, if the prices were set very high, users may not shift their demands. On contrary, if the prices were set low, consumers may not respond to the new price signals in order to cut down their energy consumption.

Table 12. Recent development in real-time pricing (RTP) pricing policy.

\begin{tabular}{|c|c|c|}
\hline Ref. & Year & Purpose \\
\hline [367] & Jan. 2019 & $\begin{array}{l}\text { The authors have proposed a distributed online pricing strategy for demand-side } \\
\text { programs under uncertainties and restricted communication links. Performing the } \\
\text { optimization process aims to allocate the minimum operating cost for the utility } \\
\text { considering time variant DRs. The proposed study has succeeded in reducing the gap } \\
\text { between the online algorithm and the offline optimization process. }\end{array}$ \\
\hline [368] & Dec. 2010 & $\begin{array}{l}\text { The authors used a least-square support vector machine to compute short-run tariffs } \\
\text { by applying a model predictive control. }\end{array}$ \\
\hline [369] & Jun. 2012 & $\begin{array}{l}\text { An optimal load management strategy for residential consumers that uses the } \\
\text { communication capability of a typical smart grid was proposed in Reference [369]. } \\
\text { The main objective was to allocate the optimal relationship between the spot price and } \\
\text { users' electrical appliances, including electric vehicles in a typical smart building. }\end{array}$ \\
\hline [370] & May 2018 & $\begin{array}{l}\text { Markov's decision-based multi-stage optimization algorithm has been proposed in } \\
\text { Reference [370] to maximize the social welfare under the RTP pricing scheme. } \\
\text { The optimization process has been divided into sub-problems; the former optimizes } \\
\text { the problem from the consumers' perspectives, while the latter is dedicated to the } \\
\text { energy supplier that uses a dual-sub gradient convex optimization. }\end{array}$ \\
\hline [394] & Jan. 2019 & $\begin{array}{l}\text { The authors have presented a real-time Energy Management System (EMS) that is } \\
\text { suitable for the rooftop PV system integrated with battery storage. The EMS is } \\
\text { grid-connected, where the price signal controls the flow of power within the system. } \\
\text { The proposed study aims to maximize the revenue over a given cycle using Lagrange } \\
\text { multiplier-based optimization algorithm. }\end{array}$ \\
\hline
\end{tabular}


The structure of a successful CPP mechanism needs to be carefully designed since the CPP possesses more constraints compared to RTP. For instance, the authors of Reference [372] developed a CPP framework to maximize the utility's profits considering end users' response to dynamic pricing, the total number of critical events, duration cycles, and peak rates. The proposed study utilized a profit index to address the impact of the previous metrics on the profits incurred. The implementation of the CPP approach resulted in a significant reduction in the average consumption of users. In Reference [373], the authors carried out a study to compare a TOU and a CPP framework to investigate the behavior of consumers under both pricing structures. The proposed analysis revealed the success of CPP over TOU in reducing the overall energy consumption. Dynamic pricing approaches may be less attractive in the distribution network where consumers lack the interest to follow price signals regularly. The authors in Reference [384] investigated the impact of applying such approaches on a group of people of different ages. Consumers were allowed to choose either to switch their electrical appliances or leaving homes during the events of higher rates. The study concluded that the dynamic pricing mechanisms have a negative impact on elders due to their restriction on mobility; thereby, they are exposed more likely to high prices. Table 13 summarizes the advancements achieved to optimize the CPP frameworks.

Table 13. Recent developments in critical peak pricing (CPP).

\begin{tabular}{|c|c|c|}
\hline Ref. & Year & Purpose \\
\hline [374] & Jun. 2018 & $\begin{array}{l}\text { The authors have combined pricing framework (RTP and CPP) to allocate the } \\
\text { optimal operation cycle for a smart home appliance based on a priority list. } \\
\text { The proposed study has used an enhanced differential evolution (EDE) and } \\
\text { teacher learning-based optimization (TLBO) to attain the maximum } \\
\text { satisfaction of consumers. }\end{array}$ \\
\hline [375] & Jan. 2019 & $\begin{array}{l}\text { A bi-level framework that aims to maximize the profits of a smart distribution } \\
\text { company with electric vehicle parking lots has been proposed. The objective is to } \\
\text { minimize the cost of energy purchased from the wholesale market for the leader } \\
\text { (e.g., distribution company) and to maximize the profits of parking lots owner } \\
\text { (e.g., follower) under Critical Pricing Policy. }\end{array}$ \\
\hline [376] & Dec. 2018 & $\begin{array}{l}\text { A mixed-integer linear programming model to allocate the optimal size and } \\
\text { optimal planning scheme of Onsite Generation System (OGS) under a Critical } \\
\text { Pricing structure has been proposed by Reference [376]. The results have } \\
\text { indicated a significant reduction in electricity cost if the OGS is appropriately } \\
\text { sized and operated. }\end{array}$ \\
\hline [370] & May 2018 & $\begin{array}{l}\text { The authors have proposed a Markov decision-based multi-stage optimization } \\
\text { algorithm to maximize the social welfare under the RTP pricing scheme. The } \\
\text { optimization process has been divided into sub-problems; the former optimizes } \\
\text { the problem from the consumers' perspectives, while the latter is dedicated to the } \\
\text { energy supplier that uses a dual-sub gradient convex optimization. }\end{array}$ \\
\hline [377] & Jun. 2018 & $\begin{array}{l}\text { A security-constrained program to schedule the supply-demand by designing an } \\
\text { optimal pricing scheme has been proposed. The proposed study aims to find the } \\
\text { best pricing modality for different demand-side programs (i.e., TOU, CPP, and } \\
\text { RTP) that improves efficiency while guaranteeing the environmental restrictions. } \\
\text { A multi-objective optimization approach has been used to minimize the ISO } \\
\text { operational cost and the greenhouse emissions resulted from the generating units. }\end{array}$ \\
\hline
\end{tabular}

\subsection{Day-Ahead Pricing}

Due to the growing developments in the industry of smart metering technologies, along with the dire need to increase the price-responsive demands, utilities have proposed and utilized various price modalities to incentivize consumers to reduce their consumption, particularly during peak periods [378]. In addition, recent studies have indicated that the exposure of end-users to hourly real-time pricing mechanisms succeeded in driving consumers to a wiser and efficient energy utilization [395-397]. RTP allows consumers to reduce their bills following the price deviation during low-periods and high-periods. However, there are some barriers associated with real-time pricing mechanisms, including regulatory concerns, lack of interest, and implementation issues. Therefore, it is essential to figure out a pricing mechanism that overcomes the barriers introduced earlier and possess advantages for both utilities and consumers. Day-Ahead Pricing (DAP) policy is a time-dependent pricing scheme 
that is set day ahead. Such a pricing scheme is more attractive to consumers since they have the ability to schedule their energy consumption, and therefore they may benefit from the operation during the off-peak periods [101]. Table 14 presents numerous strategies and progress achieved to optimize the mechanism of day-ahead pricing.

Table 14. Developments in day-ahead pricing mechanism.

\begin{tabular}{cll}
\hline Ref. & & \multicolumn{1}{c}{ Purpose } \\
\hline [380] & Jan. 2019 & $\begin{array}{l}\text { The authors have used a bi-objective optimization model to achieve a minimum } \\
\text { electricity cost and to reduce the aggregated peak demands for residential } \\
\text { Electric Vehicles (EVs) under a day ahead pricing structure. }\end{array}$ \\
\hline [381] & Jan. 2019 & $\begin{array}{l}\text { The authors have discussed the feasibility of trading electrical power as a } \\
\text { commodity in a day-ahead electricity market instead of trading energy. } \\
\text { The objective of this study is to overcome the coarse discretization that is } \\
\text { commonly seen in wholesale energy markets. }\end{array}$ \\
\hline [382] & Jan. 2019 & $\begin{array}{l}\text { The authors have proposed an optimal hourly configuration and day } \\
\text { head-pricing scheme in a smart distribution system considering the operation of } \\
\text { protective devices. The authors have used a metaheuristic-based optimization } \\
\text { model to minimize the purchasing power from the wholesale market and } \\
\text { distributed resources owners, cost of power loss, cost of switching actions, } \\
\text { and the cost of implementing the demand response Programs. }\end{array}$ \\
\hline [383] & $\begin{array}{l}\text { A game-theoretic multi-stage optimization model to simultaneously determine } \\
\text { the dynamic pricing policy for the Independent System Operator and EV parking } \\
\text { lots has been proposed. The study aims to minimize the electricity bills of EV } \\
\text { owners while ensuring the profitability of the ISO in a day-ahead } \\
\text { pricing framework. }\end{array}$ \\
\hline
\end{tabular}

Day-ahead modality looks promising approach for users and energy providers. However, there might be some challenges that need to be addressed for a successful application. The design of an optimal price beforehand may involve several factors that should be considered, such as load forecasting [398], supply availability, climatic forecasting, and energy price forecasting. Therefore, robust optimization algorithms are needed. Furthermore, since the prices are set and sent day ahead, the utility may incur a financial loss if the peak occurs during low-price periods [399].

\section{Conclusions}

A thorough review of the advances on the prevailing applications of smart grids has been presented mainly focusing on data management, cybersecurity, different pricing modalities, demand response, renewable power integration, and reliability indices. Since the various components in a smart grid generate a massive amount of data, a complete section is dedicated to investigating the flow, analysis, and management of such a broad set of heterogeneous data. The associated challenges and recent developments have also been presented. Due to the high-level penetration of informatics and communication infrastructure, which exposes the network to security vulnerabilities, the presented study has highlighted the potential sources of threats, the type of cyber-attacks, and the mathematical models that can be used to describe the attacks. The study has also highlighted the advances in detection techniques in the cyber system within the layout of smart grids. The power system is vast and complex, which is geographically spread over a wide area; therefore, increasing the immunity of the system against cyber attackers can also be a significant challenge. The majority of the pricing modalities proposed in this study are either price-based or incentive-based schemes. Therefore, consumers have little choice once the tariff rate is agreed upon. Such deficiency allows different entities to set the prices the way they want during peaking hours; thereby, consumers are obliged to follow the pricing schedule. However, the expansion in the advanced metering infrastructure increases the flexibility for consumers to control their energy consumption more effectively. The presented study has extensively investigated different pricing mechanisms that can be deployed by means of demand response. The state-of-the-art in that area has also been highlighted. Furthermore, the presented work has comprehensively reviewed the role of demand response in leveraging the transition toward the smart grid. Demand response 
can be regarded as a promising technology to promote the functionality of end-users to be more involved not only in electricity bill management but also in increasing the efficiency of the electricity market. It is pointed out that behavioral science might assist in unlocking the potentials of a successful smart grid transformation. The emerging advances in demand response applications have also been enumerated. The integration of distributed generation (DG) along with energy storage in smart grids is very imperative. We have briefly presented the recent applications in this emerging area as well. The reliability indices associated with the deployment of DGs and demand response (DR) in smart grids have also been summarized.

Author Contributions: Conceptualization, I.A. and M.K.; data curation, I.A. and M.A.A.; formal analysis, M.A.A. and A.V.S.; investigation, I.A., M.A.A., and A.V.S.; methodology, I.A. and M.K.; project administration, M.K.; resources, M.A.A. and M.K.; software, M.K.; supervision, M.K. and A.V.S.; validation, I.A.; writing-original draft, I.A. and M.K.; writing-review and editing, M.A.A. and A.V.S. All authors have read and agreed to the published version of the manuscript.

Funding: This work was supported by the Deanship of Research (DSR) at King Fahd University of Petroleum and Minerals (KFUPM), Dhahran 31261, KSA.

Acknowledgments: The authors at KFUPM would like to acknowledge the support provided by DSR at King Fahd University of Petroleum and Minerals for funding this work through project No. DF191011. The author at UNSW would like to acknowledge the support provided by the Australian Research Council. Furthermore, M.A. Abido and M. Khalid would like to acknowledge the funding support provided by the King Abdullah City for Atomic and Renewable Energy (K.A. CARE) and I. Alotaibi acknowledges the support provided by Qassim University (QU).

Conflicts of Interest: The authors declare no conflict of interest.

\section{References}

1. Nosratabadi, S.M.; Hooshmand, R.-A.; Gholipour, E. A comprehensive review on microgrid and virtual power plant concepts employed for distributed energy resources scheduling in power systems. Renew. Sustain. Energy Rev. 2017, 67, 341-363. [CrossRef]

2. Olivares, D.E.; Mehrizi-Sani, A.; Etemadi, A.H.; Cañizares, C.A.; Iravani, R.; Kazerani, M.; Hajimiragha, A.H.; Gomis-Bellmunt, O.; Saeedifard, M.; Palma-Behnke, R.; et al. Trends in Microgrid Control. IEEE Trans. Smart Grid 2014, 5, 1905-1919. [CrossRef]

3. Parhizi, S.; Lotfi, H.; Khodaei, A.; Bahramirad, S. State of the art in research on microgrids: A review. IEEE Access 2015, 3, 890-925. [CrossRef]

4. Justo, J.J.; Mwasilu, F.; Lee, J.; Jung, J.-W. AC-microgrids versus DC-microgrids with distributed energy resources: A review. Renew. Sustain. Energy Rev. 2013, 24, 387-405. [CrossRef]

5. Arunkumari, T.; Indragandhi, V. An overview of high voltage conversion ratio DC-DC converter configurations used in DC micro-grid architectures. Renew. Sustain. Energy Rev. 2017, 77, 670-687. [CrossRef]

6. Arbab-Zavar, B.; Palacios-Garcia, E.; Vasquez, J.; Guerrero, J. Smart inverters for microgrid applications: A review. Energies 2019, 12, 840. [CrossRef]

7. Zhang, Q.; Callanan, R.; Das, M.K.; Ryu, S.-H.; Agarwal, A.K.; Palmour, J.W. SiC power devices for microgrids. IEEE Trans. Power Electron. 2010, 25, 2889-2896. [CrossRef]

8. Blaabjerg, F.; Chen, Z.; Kjaer, S.B. Power electronics as efficient interface in dispersed power generation systems. IEEE Trans. Power Electron. 2004, 19, 1184-1194. [CrossRef]

9. Zhong, Q.-C.; Weiss, G. Synchronverters: Inverters that mimic synchronous generators. IEEE Trans. Ind. Electron. 2011, 58, 1259-1267. [CrossRef]

10. El-hawary, M.E. The Smart Grid-State-of-the-art and Future Trends. Electr. Power Compon. Syst. 2014, 42, 239-250. [CrossRef]

11. Independence Energy. Security act of 2007. Publiclaw 110-140. 110th Congr. Congr. Rec. 2007, 153, 110-140.

12. Bryson, J.; Gallagher, P.D. NIST framework and roadmap for smart grid interoperability standards. Natl. Inst. Stand. Technol. NIST US Dep. Commer. 2012, 227.

13. Betis, G.; Cassandras, C.G.; Nucci, C.A. Smart cities [Scanning the Issue]. Proc. IEEE 2018, 106, 513-517. [CrossRef]

14. Bi, S.; Zhang, Y.J.A. Graph-based cyber security analysis of state estimation in smart power grid. IEEE Commun. Mag. 2017, 55, 176-183. [CrossRef] 
15. Tuballa, M.L.; Abundo, M.L. A review of the development of smart grid technologies. Renew. Sustain. Energy Rev. 2016, 59, 710-725. [CrossRef]

16. Siddiqui, O. Energy Savings and Carbon Emissions Reductions Enabled by a Smart Grid; Electric Power Research Institute EPRI: Palo Alto, CA, USA, 2008; p. 64.

17. DECC. Smarter Grids: The Opportunity; Department of Energy \& Climate Change: London, UK, $2009 ;$ p. 18.

18. Ardito, L.; Procaccianti, G.; Menga, G.; Morisio, M. Smart grid technologies in Europe: An overview. Energies 2013, 6, 251-281. [CrossRef]

19. Farhangi, H. The path of the smart grid. IEEE Power Energy Mag. 2010, 8, 18-28. [CrossRef]

20. Cunjiang, Y.; Huaxun, Z.; Lei, Z. Architecture design for smart grid. Energy Procedia 2012, 17, 1524-1528. [CrossRef]

21. Irfan, M.; Iqbal, J.; Iqbal, A.; Iqbal, Z.; Riaz, R.A.; Mehmood, A. Opportunities and challenges in control of smart grids-Pakistani perspective. Renew. Sustain. Energy Rev. 2017, 71, 652-674. [CrossRef]

22. Momoh, J.A. Smart grid design for efficient and flexible power networks operation and control. In Proceedings of the 2009 IEEE/PES Power Systems Conference and Exposition, Seattle, WA, USA, 15-18 March 2009; pp. 1-8.

23. Massoud Amin, S. Smart grid: Overview, issues and opportunities. Advances and challenges in sensing, modeling, simulation, optimization and control. Eur. J. Control 2011, 17, 547-567. [CrossRef]

24. Mei, S.; Chen, L. Recent advances on smart grid technology and renewable energy integration. Sci. China Technol. Sci. 2013, 56, 3040-3048. [CrossRef]

25. Pirak, C.; Sangsuwan, T.; Buayairaksa, S. Recent advances in communication technologies for smart grid application: A review. In Proceedings of the 2014 International Electrical Engineering Congress (iEECON), Chonburi, Thailand, 19-21 March 2014; pp. 1-4.

26. Xu, Z.; Xue, Y.; Wong, K.P. Recent advancements on smart grids in China. Electr. Power Compon. Syst. 2014, 42, 251-261. [CrossRef]

27. Gharavi, H.; Ghafurian, R. Smart grid: The electric energy system of the future [Scanning the Issue]. Proc. IEEE 2011, 99, 917-921. [CrossRef]

28. Mei, S.; Chen, L. Research focuses and advance technologies of smart grid in recent years. Chin. Sci. Bull. 2012, 57, 2879-2886. [CrossRef]

29. Ismagilova, E.; Hughes, L.; Dwivedi, Y.K.; Raman, K.R. Smart cities: Advances in research-An information systems perspective. Int. J. Inf. Manag. 2019, 47, 88-100. [CrossRef]

30. Hossain, M.R.; Oo, A.M.T.; Ali, A.B.M.S. Smart Grid. In Smart Grids: Opportunities, Developments, and Trends; Ali, A.B.M.S., Ed.; Green Energy and Technology; Springer: London, UK, 2013; pp. 23-44, ISBN 978-1-4471-5210-1.

31. Tariq, F.; Dooley, L.S. Smart Grid communication and networking technologies: Recent developments and future challenges. In Smart Grids: Opportunities, Developments, and Trends; Ali, A.B.M.S., Ed.; Green Energy and Technology; Springer: London, UK, 2013; pp. 199-213, ISBN 978-1-4471-5210-1.

32. Zahran, M. Smart grid technology, vision, management and control. WSEAS Trans. J. 2013, 12, 12.

33. Nambiar, R.; Shroff, R.; Handy, S. Smart cities: Challenges and opportunities. In Proceedings of the 2018 10th International Conference on Communication Systems Networks (COMSNETS), Bengaluru, India, 3-7 January 2018; pp. 243-250.

34. Babu, N.R. Smart Grid Systems: Modeling and Control; CRC Press: Boca Raton, FL, USA, 2018.

35. 1854-2019_IEEE Standards Association Guide for Smart Distribution Applications Guide; IEEE Standards: Piscataway, NJ, USA, 2019; pp. 1-65. [CrossRef]

36. Warren, C.A. 1366-2012-IEEE Guide for Electric Power Distribution Reliability Indices; IEEE Standards Association: Piscataway, NJ, USA, 2012.

37. 1250-2018 - IEEE Guide for Identifying and Improving Voltage Quality in Power Systems; IEEE Standards Association: Piscataway, NJ, USA, 2018. [CrossRef]

38. IEEE Standards Committee IEEE Guide for Smart Grid Interoperability of Energy Technology and Information Technology Operation with the Electric Power System (EPS), End-Use Applications, and Loads. Inst. Electr. Electron. Eng. 2011.

39. IEEE Standards Association IEEE Guide for Synchronization, Calibration, Testing, and Installation of Phasor Measurement Units (PMUs) for Power System Protection and Contro. IEEE Stand. C 2013, 37.

40. C37231-2006-IEEE Standards Committee IEEE Recommended Practice for Microprocessor-Based Protection Equipment Firmware Control; IEEE Standards Association: Piscataway, NJ, USA, 2007; pp. 1-25. [CrossRef] 
41. IEEE Standards Committee IEEE Standard for Common Format for Naming Time Sequence Data Files (COMNAME); IEEE Std C37232-2011 Revis; IEEE Standards Association: Piscataway, NJ, USA, 2011; pp. 1-25. [CrossRef]

42. IEEE Standards Committee IEEE Standard Profile for Use of IEEE 1588 Precision Time Protocol in Power System Applications. IEEE PC37238D212 2017, 1-40.

43. Sato, T.; Kammen, D.M.; Duan, B.; Macuha, M.; Zhou, Z.; Wu, J.; Tariq, M.; Asfaw, S.A. Smart Grid Standards: Specifications, Requirements, and Technologies; John Wiley \& Sons: Hoboken, NJ, USA, 2015; ISBN 978-1-118-65369-2.

44. 19012-2013-Standard for Low Frequency (less than 500 kHz) Narrow Band Power Line Communications for Smart Grid Applications; IEEE Standards Association: Piscataway, NJ, USA, 2013; pp. 1-269. [CrossRef]

45. Camacho, E.F.; Samad, T.; Garcia-Sanz, M.; Hiskens, I. Control for renewable energy and smart grids. Impact Control Technol. Control Syst. Soc. 2011, 69-88.

46. Samarakoon, K.; Ekanayake, J.; Jenkins, N. Investigation of domestic load control to provide primary frequency response using smart meters. IEEE Trans. Smart Grid 2012, 3, 282-292. [CrossRef]

47. Samarakoon, K.; Ekanayake, J. Demand side primary frequency response support through smart meter control. In Proceedings of the 2009 44th International Universities Power Engineering Conference (UPEC), Glasgow, UK, 1-4 September 2009; pp. 1-5.

48. Yu, S.; Chau, T.K.; Fernando, T.; Savkin, A.V.; Iu, H.H.-C. Novel quasi-decentralized SMC-based frequency and voltage stability enhancement strategies using valve position control and FACTS device. IEEE Access 2017, 5, 946-955. [CrossRef]

49. Shi, Y.; Tuan, H.D.; Duong, T.Q.; Poor, H.V.; Savkin, A.V. PMU placement optimization for efficient state estimation in smart grid. IEEE J. Sel. Areas Commun. 2020, 38, 71-83. [CrossRef]

50. Gharani Khajeh, K.; Bashar, E.; Mahboub Rad, A.; Gharehpetian, G.B. Integrated model considering effects of zero injection buses and conventional measurements on optimal PMU placement. IEEE Trans. Smart Grid 2015, 8, 1006-1013. [CrossRef]

51. Esmaili, M.; Gharani, K.; Shayanfar, H.A. Redundant observability PMU placement in the presence of flow measurements considering contingencies. IEEE Trans. Power Syst. 2013, 28, 3765-3773. [CrossRef]

52. Ou, T.-C.; Tsao, T.-P.; Hong, C.-M.; Chen, C.-H. Hybrid control system for automatic voltage regulator in smart grid. In Proceedings of the 2013 International Conference on Machine Learning and Cybernetics, Tianjin, China, 14-17 July 2013; Volume 3, pp. 1103-1108.

53. Sridhar, S.; Govindarasu, M. Model-based attack detection and mitigation for automatic generation control. IEEE Trans. Smart Grid 2014, 5, 580-591. [CrossRef]

54. Schneider Electric. GIS-Based Design for Effective Smart Grid Strategies; Schneider Electric Inc.: Fort Collins, CO, USA, 2012.

55. Environmental Systems Research Institute (ESRI). Enterprise GIS and the Smart Electric Grid; ESRI: Redlands, CA, USA, 2009; p. 11.

56. Dirkman, J. Best Practices for Creating Your Smart Grid Network Model; Schneider Electric Inc.: Fort Collins, CO, USA, 2013.

57. Keyhani, A.; Chatterjee, A. Automatic generation control structure for smart power grids. IEEE Trans. Smart Grid 2012, 3, 1310-1316. [CrossRef]

58. Rahman, F.; Rehman, S.; Abdul-Majeed, M.A. Overview of energy storage systems for storing electricity from renewable energy sources in Saudi Arabia. Renew. Sustain. Energy Rev. 2012, 16, 274-283. [CrossRef]

59. Ipakchi, A.; Albuyeh, F. Grid of the future. IEEE Power Energy Mag. 2009, 7, 52-62. [CrossRef]

60. Nafi, N.S.; Ahmed, K.; Gregory, M.A.; Datta, M. A survey of smart grid architectures, applications, benefits and standardization. J. Netw. Comput. Appl. 2016, 76, 23-36. [CrossRef]

61. Fang, X.; Misra, S.; Xue, G.; Yang, D. Smart grid-The new and improved power grid: A survey. IEEE Commun. Surv. Tutor. 2012, 14, 944-980. [CrossRef]

62. Keeping, S. Carbon Emission Reductions by the Implementation of a Smart Grid; NOJA Power: Murarrie, Queensland, Australia, 2013.

63. Chandan, A.; Potdar, V.; Nandi, C. Smart Cities; Springer International Publishing AG: Cham, Switzerland, 2018; ISBN 978-3-319-76668-3.

64. Wade, N.S.; Taylor, P.C.; Lang, P.D.; Jones, P.R. Evaluating the benefits of an electrical energy storage system in a future smart grid. Energy Policy 2010, 38, 7180-7188. [CrossRef] 
65. Li, N.; Ni, Y.; Sun, S.; Yao, M.Q. Survey on smart grid and relevant key technologies. South. Power Syst. Technol. 2010, 4, 1-7.

66. Borlase, S. Smart Grids: Infrastructure, Technology, and Solutions; CRC Press: Boca Raton, FL, USA, 2013.

67. Xie, K.; Liu, Y.; Zhu, Z.; Yu, E. The vision of future smart grid. Electr. Power 2008, 6.

68. Hamilton, B.; Summy, M. Benefits of the smart grid [in my view]. IEEE Power Energy Mag. 2011, 9, 102-104. [CrossRef]

69. Moslehi, K.; Kumar, R. A reliability perspective of the smart grid. IEEE Trans. Smart Grid 2010, 1, 57-64. [CrossRef]

70. Mehigan, L.; Deane, J.P.; Gallachóir, B.P.Ó.; Bertsch, V. A review of the role of distributed generation (DG) in future electricity systems. Energy 2018, 163, 822-836. [CrossRef]

71. Allan, G.; Eromenko, I.; Gilmartin, M.; Kockar, I.; McGregor, P. The economics of distributed energy generation: A literature review. Renew. Sustain. Energy Rev. 2015, 42, 543-556. [CrossRef]

72. Vahl, F.P.; Rüther, R.; Casarotto Filho, N. The influence of distributed generation penetration levels on energy markets. Energy Policy 2013, 62, 226-235. [CrossRef]

73. Kakran, S.; Chanana, S. Smart operations of smart grids integrated with distributed generation: A review. Renew. Sustain. Energy Rev. 2018, 81, 524-535. [CrossRef]

74. Abdmouleh, Z.; Gastli, A.; Ben-Brahim, L.; Haouari, M.; Al-Emadi, N.A. Review of optimization techniques applied for the integration of distributed generation from renewable energy sources. Renew. Energy 2017, 113, 266-280. [CrossRef]

75. Paliwal, P.; Patidar, N.P.; Nema, R.K. Planning of grid integrated distributed generators: A review of technology, objectives and techniques. Renew. Sustain. Energy Rev. 2014, 40, 557-570. [CrossRef]

76. Ackermann, T.; Andersson, G.; Söder, L. Distributed generation: A definition. Electr. Power Syst. Res. 2001, 57, 195-204. [CrossRef]

77. Distributed Energy Resources; North American Electric Reliability Corporation (NERC): Atlanta, GA, USA, 2017; p. 50.

78. Bayod-Rújula, A.A. Future development of the electricity systems with distributed generation. Energy 2009, 34, 377-383. [CrossRef]

79. Chmutina, K.; Goodier, C.I. Alternative future energy pathways: Assessment of the potential of innovative decentralised energy systems in the UK. Energy Policy 2014, 66, 62-72. [CrossRef]

80. Adil, A.M.; Ko, Y. Socio-technical evolution of Decentralized Energy Systems: A critical review and implications for urban planning and policy. Renew. Sustain. Energy Rev. 2016, 57, 1025-1037. [CrossRef]

81. Singh, B.; Sharma, J. A review on distributed generation planning. Renew. Sustain. Energy Rev. 2017, 76, 529-544. [CrossRef]

82. Kim, W.-W.; Park, J.-K.; Yoon, Y.-T.; Kim, M.-K. Transmission expansion planning under uncertainty for investment options with various lead-times. Energies 2018, 11, 2429. [CrossRef]

83. Howell, S.; Rezgui, Y.; Hippolyte, J.-L.; Jayan, B.; Li, H. Towards the next generation of smart grids: Semantic and holonic multi-agent management of distributed energy resources. Renew. Sustain. Energy Rev. 2017, 77, 193-214. [CrossRef]

84. Oliva, H.S. Residential energy efficiency and distributed generation-Natural partners or competition? Renew. Sustain. Energy Rev. 2017, 76, 932-940. [CrossRef]

85. Pepermans, G.; Driesen, J.; Haeseldonckx, D.; Belmans, R.; D’haeseleer, W. Distributed generation: Definition, benefits and issues. Energy Policy 2005, 33, 787-798. [CrossRef]

86. William, E.L.; Luke, J.R.; Liam, D.W.; Colin, F.A.; Anthony, R.S. An economic evaluation of the potential for distributed energy in Australia. Energy Policy 2012, 51, 277-289. [CrossRef]

87. Rouhani, A.; Hosseini, S.H.; Raoofat, M. Composite generation and transmission expansion planning considering distributed generation. Int. J. Electr. Power Energy Syst. 2014, 62, 792-805. [CrossRef]

88. Khalid, M.; Ahmadi, A.; Savkin, A.V.; Agelidis, V.G. Minimizing the energy cost for microgrids integrated with renewable energy resources and conventional generation using controlled battery energy storage. Renew. Energy 2016, 97, 646-655. [CrossRef]

89. Huda, A.S.N.; Živanović, R. Large-scale integration of distributed generation into distribution networks: Study objectives, review of models and computational tools. Renew. Sustain. Energy Rev. 2017, 76, 974-988. [CrossRef]

90. Kiani Rad, H.; Moravej, Z. Coordinated transmission substations and sub-transmission networks expansion planning incorporating distributed generation. Energy 2017, 120, 996-1011. [CrossRef] 
91. Moghimi, H.; Ahmadi, A.; Aghaei, J.; Rabiee, A. Stochastic techno-economic operation of power systems in the presence of distributed energy resources. Int. J. Electr. Power Energy Syst. 2013, 45, 477-488. [CrossRef]

92. Jain, S.; Kalambe, S.; Agnihotri, G.; Mishra, A. Distributed generation deployment: State-of-the-art of distribution system planning in sustainable era. Renew. Sustain. Energy Rev. 2017, 77, 363-385. [CrossRef]

93. Zhuo, W.; Savkin, A.V.; Meng, K. Decentralized optimal control of a microgrid with solar PV, BESS and thermostatically controlled loads. Energies 2019, 12, 2111. [CrossRef]

94. Labis, P.E.; Visande, R.G.; Pallugna, R.C.; Caliao, N.D. The contribution of renewable distributed generation in mitigating carbon dioxide emissions. Renew. Sustain. Energy Rev. 2011, 15, 4891-4896. [CrossRef]

95. Morstyn, T.; Savkin, A.V.; Hredzak, B.; Tuan, H.D. Scalable energy management for low voltage microgrids using multi-agent storage system aggregation. IEEE Trans. Power Syst. 2018, 33, 1614-1623. [CrossRef]

96. Pesaran, M.H.A.; Huy, P.D.; Ramachandaramurthy, V.K. A review of the optimal allocation of distributed generation: Objectives, constraints, methods, and algorithms. Renew. Sustain. Energy Rev. 2017, 75, 293-312. [CrossRef]

97. Khalid, M. An optimal operation of wind energy storage system for frequency control based on model predictive control. Renew. Energy 2012, 48, 127-132. [CrossRef]

98. L'Abbate, A.; Fulli, G.; Starr, F.; European Commission. Distributed Power Generation in Europe: Technical Issues for Further Integration; EUR 23234 EN-2007; European Commission: Brussels, Belgium, 2007.

99. Carley, S. Distributed generation: An empirical analysis of primary motivators. Energy Policy 2009, 37, 1648-1659. [CrossRef]

100. Heo, J.-H.; Kim, M.-K.; Park, G.-P.; Yoon, Y.T.; Park, J.K.; Lee, S.-S.; Kim, D.-H. A reliability-centered approach to an optimal maintenance strategy in transmission systems using a genetic algorithm. IEEE Trans. Power Deliv. 2011, 26, 2171-2179. [CrossRef]

101. Khatamianfar, A.; Khalid, M.; Savkin, A.V.; Agelidis, V.G. Improving wind farm dispatch in the Australian electricity market with battery energy storage using model predictive control. IEEE Trans. Sustain. Energy 2013, 4, 745-755. [CrossRef]

102. Khalid, M.; AlMuhaini, M.; Aguilera, R.P.; Savkin, A.V. Method for planning a wind-solar-battery hybrid power plant with optimal generation-demand matching. IET Renew. Power Gener. 2018, 12, 1800-1806. [CrossRef]

103. Khalid, M. Wind power economic dispatch-Impact of radial basis functional networks and battery energy storage. IEEE Access 2019, 7, 36819-36832. [CrossRef]

104. Morstyn, T.; Hredzak, B.; Agelidis, V.G. Control strategies for microgrids with distributed energy storage systems: An overview. IEEE Trans. Smart Grid 2018, 9, 3652-3666. [CrossRef]

105. Saad, W.; Han, Z.; Poor, H.; Basar, T. Game-theoretic methods for the smart grid: An overview of microgrid systems, demand-side management, and smart grid communications. IEEE Signal Process. Mag. 2012, 29, 86-105. [CrossRef]

106. Morstyn, T.; Demetriades, G.D.; Agelidis, V.G. Unified distributed control for DC microgrid operating modes. IEEE Trans. Power Syst. 2015, 31, 802-812. [CrossRef]

107. Global DER Deployment Forecast Database; Navigant Research: Boulder, CO, USA, 2017; p. 40.

108. Distributed Energy Resources: Technical Considerations for the Bulk Power System; Federal Energy Regulatory Commission (FERC): Washington, DC, USA, 2018; p. 47.

109. Han, J.; Ouyang, L.; Xu, Y.; Zeng, R.; Kang, S.; Zhang, G. Current status of distributed energy system in China. Renew. Sustain. Energy Rev. 2016, 55, 288-297. [CrossRef]

110. Albasrawi, M.N.; Jarus, N.; Joshi, K.A.; Sarvestani, S.S. Analysis of reliability and resilience for smart grids. In Proceedings of the 2014 IEEE 38th Annual Computer Software and Applications Conference, Vasteras, Sweden, 21-25 July 2014; pp. 529-534.

111. Xu, S.; Qian, Y.; Hu, R.Q. On reliability of smart grid neighborhood area networks. IEEE Access 2015, 3, 2352-2365. [CrossRef]

112. Bose, A. Models and techniques for the reliability analysis of the smart grid. In Proceedings of the IEEE PES General Meeting, Providence, RI, USA, 25-29 July 2010; pp. 1-5.

113. Ilie, I.; Hernando-Gil, I.; Collin, A.J.; Acosta, J.L.; Djokic, S.Z. Reliability performance assessment in smart grids with demand-side management. In Proceedings of the 2011 2nd IEEE PES International Conference and Exhibition on Innovative Smart Grid Technologies, Manchester, UK, 5-7 December 2011; pp. 1-7.

114. Karki, R.; Billinton, R.; Verma, A.K. Reliability Modeling and Analysis of Smart Power Systems; Springer India Private Limited: New Delhi, India, 2014; ISBN 978-81-322-1798-5. 
115. Moslehi, K.; Kumar, R. Smart Grid-A reliability perspective. In Proceedings of the 2010 Innovative Smart Grid Technologies (ISGT), Gothenburg, Sweden, 19-21 January 2010; pp. 1-8.

116. Marashi, K.; Sarvestani, S.S. Towards comprehensive modeling of reliability for smart grids: Requirements and challenges. In Proceedings of the 2014 IEEE 15th International Symposium on High-Assurance Systems Engineering, Miami Beach, FL, USA, 9-11 January 2014; pp. 105-112.

117. Liu, Y.; Deng, L.; Gao, N.; Sun, X. A reliability assessment method of cyber physical distribution system. Energy Procedia 2019, 158, 2915-2921. [CrossRef]

118. Kazemi, S. Reliability Evaluation of Smart Distribution Grids; Aalto University, School of Electrical Engineering: Espoo, Finland, 2011.

119. Chren, S.; Rossi, B.; Bühnova, B.; Pitner, T. Reliability data for smart grids: Where the real data can be found. In Proceedings of the 2018 Smart City Symposium Prague (SCSP), Prague, Czech Republic, 24-25 May 2018; pp. 1-6.

120. Aravinthan, V.; Balachandran, T.; Ben-Idris, M.; Fei, W.; Heidari-Kapourchali, M.; Hettiarachchige-Don, A.; Jiang, J.N.; Lei, H.; Liu, C.-C.; Mitra, J.; et al. Reliability modeling considerations for emerging cyber-physical power systems. In Proceedings of the 2018 IEEE International Conference on Probabilistic Methods Applied to Power Systems (PMAPS), Boise, ID, USA, 24-28 June 2018; pp. 1-7.

121. Wadi, M.; Baysal, M.; Shobole, A.; Tur, M.R. Reliability evaluation in smart grids via modified monte carlo simulation method. In Proceedings of the 2018 7th International Conference on Renewable Energy Research and Applications (ICRERA), Paris, France, 14-17 October 2018; pp. 841-845.

122. Kornatka, M. Distribution of SAIDI and SAIFI indices and the saturation of the MV network with remotely controlled switches. In Proceedings of the 2017 18th International Scientific Conference on Electric Power Engineering (EPE), Kouty nad Desnou, Prague, Czech Republic, 17-19 May 2017; pp. 1-4.

123. Brown, R. Electric Power Distribution Reliability, Second Edition; Power Engineering (Willis); CRC Press: Boca Raton, FL, USA, 2008; Volume 20081087, ISBN 978-0-8493-7567-5.

124. Billinton, R. Distribution system reliability indices. IEEE Trans. Power Deliv. 1989, 4, 561-568. [CrossRef]

125. EPRI. Electric Power System Resiliency: Challenges and Opportunities; Electric Power Research Institute: Palo Alto, CA, USA, 2016; p. 56.

126. Escalera, A.; Hayes, B.; Prodanović, M. A survey of reliability assessment techniques for modern distribution networks. Renew. Sustain. Energy Rev. 2018, 91, 344-357. [CrossRef]

127. Allan, R.N.; Billinton, R. Reliability Evaluation of Power Systems; Springer: Boston, MA, USA, 1996; ISBN 978-0-306-45259-8.

128. Dialynas, E.N.; Allan, R.N. Local generating facilities in the reliability evaluation of power distribution systems. IEEE Trans. Power Syst. 1986, 1, 62-67. [CrossRef]

129. Bae, I.; Kim, J. Reliability Evaluation of Distributed Generation Based on Operation Mode. IEEE Trans. Power Syst. 2007, 22, 785-790. [CrossRef]

130. Billinton, R. Reliability benefit analysis of adding WTG to a distribution system. IEEE Trans. Energy Convers. 2001, 16, 134-139. [CrossRef]

131. Wang, P.; Billinton, R. Time-sequential simulation technique for rural distribution system reliability cost/worth evaluation including wind generation as alternative supply. Transm. Distrib. IEEE Proc. Gener. 2001, 148, 355-360. [CrossRef]

132. Atwa, Y.M.; El-Saadany, E.F. Reliability evaluation for distribution system with renewable distributed generation during islanded mode of operation. IEEE Trans. Power Syst. 2009, 24, 572-581. [CrossRef]

133. Conti, S.; Rizzo, S.A. Monte carlo simulation by using a systematic approach to assess distribution system reliability considering intentional islanding. IEEE Trans. Power Deliv. 2015, 30, 64-73. [CrossRef]

134. Celli, G.; Ghiani, E.; Pilo, F.; Soma, G.G. Reliability assessment in smart distribution networks. Electr. Power Syst. Res. 2013, 104, 164-175. [CrossRef]

135. Guo, H.; Levi, V.; Buhari, M. Reliability assessment of smart distribution networks. In Proceedings of the 2015 IEEE Innovative Smart Grid Technologies-Asia (ISGT ASIA), Bangkok, Thailand, 3-6 November 2015; pp. 1-6.

136. Fotuhi-Firuzabad, M.; Rajabi-Ghahnavie, A. An analytical method to consider DG impacts on distribution system reliability. In Proceedings of the 2005 IEEE/PES Transmission Distribution Conference Exposition: Asia and Pacific, Dalian, China, 18 August 2005; pp. 1-6. 
137. Conti, S.; Nicolosi, R.; Rizzo, S.A. Generalized systematic approach to assess distribution system reliability with renewable distributed generators and microgrids. IEEE Trans. Power Deliv. 2012, 27, 261-270. [CrossRef]

138. Al-Muhaini, M.; Heydt, G.T. Evaluating future power distribution system reliability including distributed generation. IEEE Trans. Power Deliv. 2013, 28, 2264-2272. [CrossRef]

139. Conti, S.; Rizzo, S.A. Modelling of microgrid-renewable generators accounting for power-output correlation. IEEE Trans. Power Deliv. 2013, 28, 2124-2133. [CrossRef]

140. Zou, K.; Agalgaonkar, A.P.; Muttaqi, K.M.; Perera, S. An analytical approach for reliability evaluation of distribution systems containing dispatchable and nondispatchable renewable DG units. IEEE Trans. Smart Grid 2014, 5, 2657-2665. [CrossRef]

141. Chen, C.; Wu, W.; Zhang, B.; Singh, C. An analytical adequacy evaluation method for distribution networks considering protection strategies and distributed generators. IEEE Trans. Power Deliv. 2015, 30, 1392-1400. [CrossRef]

142. Conti, S.; Faraci, G.; La Corte, A.; Nicolosi, R.; Rizzo, S.A.; Schembra, G. Effect of islanding and telecontrolled switches on distribution system reliability considering load and green-energy fluctuations. Appl. Sci. 2016, 6, 138. [CrossRef]

143. De Castro, C.L.C.; Rodrigues, A.B.; Silva, M.G. Reliability evaluation of radial distribution systems considering voltage drop constraints in the restoration process. In Proceedings of the 2004 International Conference on Probabilistic Methods Applied to Power Systems, Ames, IA, USA, 12-16 September 2004; pp. 106-111.

144. Neto, A.C.; Da Silva, M.G.; Rodrigues, A.B. Impact of distributed generation on reliability evaluation of radial distribution systems under network constraints. In Proceedings of the 2006 International Conference on Probabilistic Methods Applied to Power Systems, Stockholm, Sweden, 11-15 June 2006; pp. 1-6.

145. Da Silva, A.M.L.; Nascimento, L.C.; Da Rosa, M.A.; Issicaba, D.; Lopes, J.A.P. Distributed energy resources impact on distribution system reliability under load transfer restrictions. IEEE Trans. Smart Grid 2012, 3, 2048-2055. [CrossRef]

146. Abdullah, M.A.; Agalgaonkar, A.P.; Muttaqi, K.M. Assessment of energy supply and continuity of service in distribution network with renewable distributed generation. Appl. Energy 2014, 113, 1015-1026. [CrossRef]

147. Michael, L.; Aslam, O.; Foster, B.; Kathan, D.; Kwok, J.; Medearis, L.; Palmer, R.; Sporborg, P.; Tita, M. Assessment of demand response and advanced metering. Fed. Energy Regul. Comm. Tech Rep 2013.

148. Yan, X.; Ozturk, Y.; Hu, Z.; Song, Y. A review on price-driven residential demand response. Renew. Sustain. Energy Rev. 2018, 96, 411-419. [CrossRef]

149. Gelazanskas, L.; Gamage, K.A.A. Demand side management in smart grid: A review and proposals for future direction. Sustain. Cities Soc. 2014, 11, 22-30. [CrossRef]

150. Strüker, J.; Dinther, C. Demand response in smart grids: Research opportunities for the IS discipline. In Proceedings of the Americas conference on Information Systems (AMCIS), Seattle, WA, USA, 9-12 August 2012; Volume 7.

151. Good, N.; Ellis, K.A.; Mancarella, P. Review and classification of barriers and enablers of demand response in the smart grid. Renew. Sustain. Energy Rev. 2017, 72, 57-72. [CrossRef]

152. Deng, R.; Yang, Z.; Chow, M.-Y.; Chen, J. A survey on demand response in smart grids: Mathematical models and approaches. IEEE Trans. Ind. Inform. 2015, 11, 570-582. [CrossRef]

153. Zhu, Q.; Sauer, P.; Başar, T. Value of demand response in the smart grid. In Proceedings of the 2013 IEEE Power and Energy Conference at Illinois (PECI), Champaign, IL, USA, 22-23 February 2013; pp. 76-82.

154. Warren, P. A review of demand-side management policy in the UK. Renew. Sustain. Energy Rev. 2014, 29, 941-951. [CrossRef]

155. Wu, Y.-K.; Tang, K.-T. Frequency support by demand response-Review and analysis. Energy Procedia 2019, 156, 327-331. [CrossRef]

156. Albadi, M.H.; El-Saadany, E.F. Demand response in electricity markets: An overview. In Proceedings of the 2007 IEEE Power Engineering Society General Meeting, Tampa, FL, USA, 24-28 June 2007; pp. 1-5.

157. Mohagheghi, S.; Yang, F.; Falahati, B. Impact of demand response on distribution system reliability. In Proceedings of the 2011 IEEE Power and Energy Society General Meeting, Detroit, MI, USA, 24-28 July 2011; pp. 1-7.

158. Syrri, A.L.A.; Mancarella, P. Reliability and risk assessment of post-contingency demand response in smart distribution networks. Sustain. Energy Grids Netw. 2016, 7, 1-12. [CrossRef] 
159. Xie, H.; Bie, Z.; Hua, B.; Li, G. Reliability assessment of distribution power systems considering the TOU pricing. In Proceedings of the 2013 IEEE International Conference of IEEE Region 10 (TENCON 2013), Xi'an, China, 23-25 October 2013; pp. 1-4.

160. Zeng, B.; Wu, G.; Wang, J.; Zhang, J.; Zeng, M. Impact of behavior-driven demand response on supply adequacy in smart distribution systems. Appl. Energy 2017, 202, 125-137. [CrossRef]

161. Safdarian, A.; Degefa, M.Z.; Lehtonen, M.; Fotuhi-Firuzabad, M. Distribution network reliability improvements in presence of demand response. Transm. Distrib. IET Gener. 2014, 8, 2027-2035. [CrossRef]

162. Syrri, A.L.A.; Mancarella, P. Reliability evaluation of demand response to increase distribution network utilisation. In Proceedings of the 2014 International Conference on Probabilistic Methods Applied to Power Systems (PMAPS), Durham, UK, 7-10 July 2014; pp. 1-6.

163. Drysdale, B.; Wu, J.; Jenkins, N. Flexible demand in the GB domestic electricity sector in 2030. Appl. Energy 2015, 139, 281-290. [CrossRef]

164. Jin, X.; Mu, Y.; Jia, H.; Wu, J.; Jiang, T.; Yu, X. Dynamic economic dispatch of a hybrid energy microgrid considering building based virtual energy storage system. Appl. Energy 2016, 194, 386-398. [CrossRef]

165. Cheng, M.; Sami, S.S.; Wu, J. Benefits of using virtual energy storage system for power system frequency response. Appl. Energy 2017, 194, 376-385. [CrossRef]

166. Cheng, M.; Wu, J.; Ekanayake, J.; Coleman, T.; Hung, W.; Jenkins, N. Primary frequency response in the great britain power system from dynamically controlled refrigerators. In Proceedings of the 22nd International Conference and Exhibition on Electricity Distribution (CIRED 2013, Institution of Engineering and Technology, Stockholm, Sweden, 10-13 June 2013; p. 507.

167. Short, J.A.; Infield, D.G.; Freris, L.L. Stabilization of grid frequency through dynamic demand control. IEEE Trans. Power Syst. 2007, 22, 1284-1293. [CrossRef]

168. Cheng, M.; Wu, J.; Galsworthy, S.J.; Ugalde-Loo, C.E.; Gargov, N.; Hung, W.W.; Jenkins, N. Power system frequency response from the control of bitumen tanks. IEEE Trans. Power Syst. 2016, 31, 1769-1778. [CrossRef]

169. Elamari, K.; Lopes, L.A.C.; Tonkoski, R. Using Electric Water Heaters (EWHs) for Power Balancing and Frequency Control in PV-Diesel Hybrid Mini-Grids. In Proceedings of the World Renewable Energy Congress-Sweden, Linköping, Sweden, 8-13 May 2011; pp. 842-850.

170. Tokudome, M.; Tanaka, K.; Senjyu, T.; Yona, A.; Funabashi, T.; Kim, C.-H. Frequency and voltage control of small power systems by decentralized controllable loads. In Proceedings of the 2009 International Conference on Power Electronics and Drive Systems (PEDS), Taipei, Taiwan, 2-5 November 2009; pp. 666-671.

171. Cheng, M.; Wu, J.; Galsworthy, S.; Jenkins, N.; Hung, W. Availability of load to provide frequency response in the great Britain power system. In Proceedings of the 2014 Power Systems Computation Conference, Wroclaw, Poland, 18-22 August 2014; pp. 1-7.

172. Yao, Y.; Zhang, P.; Wang, Y. A two-layer control method for thermostatically controlled loads to provide fast frequency regulation. Proc. Chin. Soc. Electr. Eng. 2018, 38, 4987-4998. [CrossRef]

173. Yan, S.; Wang, M.-H.; Yang, T.-B.; Hui, S.Y.R. Instantaneous frequency regulation of microgrids via power shedding of smart load and power limiting of renewable generation. In Proceedings of the IEEE Energy Conversion Congress and Exposition (ECCE), Milwaukee, WI, USA, 18-22 September 2016.

174. Pourmousavi, S.A.; Nehrir, M.H. Real-time central demand response for primary frequency regulation in microgrids. IEEE Trans. Smart Grid 2012, 3, 1988-1996. [CrossRef]

175. Liu, H.; Hu, Z.; Song, Y.; Wang, J.; Xie, X. Vehicle-to-grid control for supplementary frequency regulation considering charging demands. IEEE Trans. Power Syst. 2015, 30, 3110-3119. [CrossRef]

176. Faisal, M.; Hannan, M.A.; Ker, P.J.; Hussain, A.; Mansor, M.B.; Blaabjerg, F. Review of energy storage system technologies in microgrid applications: Issues and challenges. IEEE Access 2018, 6, 35143-35164. [CrossRef]

177. Mwasilu, F.; Justo, J.J.; Kim, E.-K.; Do, T.D.; Jung, J.-W. Electric vehicles and smart grid interaction: A review on vehicle to grid and renewable energy sources integration. Renew. Sustain. Energy Rev. 2014, 34, 501-516. [CrossRef]

178. Zhang, W.; Qiu, M.; Lai, X. Application of energy storage technologies in power grids. Power Syst. Technol. 2008, 7, 3-9.

179. Carpinelli, G.; Celli, G.; Mocci, S.; Mottola, F.; Pilo, F.; Proto, D. Optimal integration of distributed energy storage devices in smart grids. IEEE Trans. Smart Grid 2013, 4, 985-995. [CrossRef]

180. Akinyele, D.O.; Rayudu, R.K. Review of energy storage technologies for sustainable power networks. Sustain. Energy Technol. Assess. 2014, 8, 74-91. [CrossRef] 
181. Guney, M.S.; Tepe, Y. Classification and assessment of energy storage systems. Renew. Sustain. Energy Rev. 2017, 75, 1187-1197. [CrossRef]

182. Khodadoost Arani, A.A.B.; Gharehpetian, G.; Abedi, M. Review on energy storage systems control methods in microgrids. Int. J. Electr. Power Energy Syst. 2019, 107, 745-757. [CrossRef]

183. Khalid, M. A review on the selected applications of battery-supercapacitor hybrid energy storage systems for microgrids. Energies 2019, 12, 4559. [CrossRef]

184. Bragard, M.; Soltau, N.; Thomas, S.; Doncker, R.W.D. The balance of renewable sources and user demands in grids: Power electronics for modular battery energy storage systems. IEEE Trans. Power Electron. 2010, 25, 3049-3056. [CrossRef]

185. Griffiths, B.W. Reducing emissions from consumer energy storage using retail rate design. Energy Policy 2019, 129, 481-490. [CrossRef]

186. Terlouw, T.; AlSkaif, T.; Bauer, C.; Van Sark, W. Multi-objective optimization of energy arbitrage in community energy storage systems using different battery technologies. Appl. Energy 2019, 239, 356-372. [CrossRef]

187. Anderson, K.; Rajagopal, R.; Gamal, A.E. Coordination of distributed energy storage under spatial and temporal data asymmetry. IEEE Trans. Smart Grid 2019, 10, 1184-1194. [CrossRef]

188. Sadat, S.A.; Dai, R.; Charkhgard, H. Bi-objective mixed integer program for energy storage sharing considering storage lifetime maintenance. In Proceedings of the IEEE Power and Energy Society General Meeting, Portland, OR, USA, 5-10 August 2018.

189. Lee, H.C.; Kim, H.; Yoon, Y.T. Optimal ESS investment strategies for energy arbitrage by market structures and participants. J. Electr. Eng. Technol. 2018, 13, 51-59. [CrossRef]

190. Chapaloglou, S.; Nesiadis, A.; Iliadis, P.; Atsonios, K.; Nikolopoulos, N.; Grammelis, P.; Yiakopoulos, C.; Antoniadis, I.; Kakaras, E. Smart energy management algorithm for load smoothing and peak shaving based on load forecasting of an island's power system. Appl. Energy 2019, 627-642. [CrossRef]

191. Taylor, Z.; Akhavan-Hejazi, H.; Cortez, E.; Alvarez, L.; Ula, S.; Barth, M.; Mohsenian-Rad, H. Customer-side SCADA-assisted large battery operation optimization for distribution feeder peak load shaving. IEEE Trans. Smart Grid 2019, 10, 992-1004. [CrossRef]

192. Yang, H.; Zhang, Y.; Ma, Y.; Zhou, M.; Yang, X. Reliability evaluation of power systems in the presence of energy storage system as demand management resource. Int. J. Electr. Power Energy Syst. 2019, 110, 1-10. [CrossRef]

193. Akram, U.; Khalid, M. A coordinated frequency regulation framework based on hybrid battery-ultracapacitor energy storage technologies. IEEE Access 2018, 6, 7310-7320. [CrossRef]

194. Canevese, S.; Gatti, A.; Micolano, E.; Pellegrino, L.; Rapizza, M. Battery energy storage systems for frequency regulation: Simplified aging evaluation. In Proceedings of the 6th International Conference on Clean Electrical Power (ICCEP), Santa Margherita Ligure, Italy, 7-29 June 2017; pp. 291-297.

195. Fang, J.; Tang, Y.; Li, H.; Li, X. A Battery/ultracapacitor hybrid energy storage system for implementing the power management of virtual synchronous generators. IEEE Trans. Power Electron. 2018, 33, 2820-2824. [CrossRef]

196. Kumar, K.N.; Vijayakumar, K.; Kalpesh, C. Virtual energy storage capacity estimation using ANN-based kWh modelling of refrigerators. IET Smart Grid 2018, 1, 31-39. [CrossRef]

197. Guerrero, J.M.; Loh, P.C.; Lee, T.; Chandorkar, M. Advanced control architectures for intelligent microgrids-Part II: Power quality, energy storage, and AC/DC microgrids. IEEE Trans. Ind. Electron. 2013, 60, 1263-1270. [CrossRef]

198. Díaz-González, F.; Sumper, A.; Gomis-Bellmunt, O.; Villafáfila-Robles, R. A review of energy storage technologies for wind power applications. Renew. Sustain. Energy Rev. 2012, 16, 2154-2171. [CrossRef]

199. Khan, K.A.; Khalid, M. Hybrid energy storage system for voltage stability in a DC microgrid using a modified control strategy. In Proceedings of the 2019 IEEE Innovative Smart Grid Technologies-Asia (ISGT Asia), Chengdu, China, 21-24 May 2019; pp. 2760-2765.

200. Li, Y.; Yang, Z.; Li, G.; Zhao, D.; Tian, W. Optimal scheduling of an isolated microgrid with battery storage considering load and renewable generation uncertainties. IEEE Trans. Ind. Electron. 2018, 66, 1565-1575. [CrossRef]

201. Morstyn, T.; Hredzak, B.; Agelidis, V.G. Communication delay robustness for multi-agent state of charge balancing between distributed AC microgrid storage systems. In Proceedings of the 2015 IEEE Conference on Control Applications (CCA), Sydney, Australia, 21-23 September 2015; pp. 181-186. 
202. Feltes, J.W.; Grande-Moran, C. Black start studies for system restoration. In Proceedings of the 2008 IEEE Power and Energy Society General Meeting-Conversion and Delivery of Electrical Energy in the 21st Century, Pittsburgh, PA, USA, 20-24 July 2008; pp. 1-8.

203. Khalid, M.; Savkin, A.V. A model predictive control approach to the problem of wind power smoothing with controlled battery storage. Renew. Energy 2010, 35, 1520-1526. [CrossRef]

204. Saez-de-Ibarra, A.; Milo, A.; Gaztañaga, H.; Etxeberria-Otadui, I.; Rodríguez, P.; Bacha, S.; Debusschere, V. Analysis and comparison of battery energy storage technologies for grid applications. In Proceedings of the 2013 IEEE Grenoble Conference, Grenoble, France, 16-20 June 2013; pp. 1-6.

205. Leou, R.-C. An economic analysis model for the energy storage system applied to a distribution substation. Int. J. Electr. Power Energy Syst. 2012, 34, 132-137. [CrossRef]

206. Hill, C.A.; Such, M.C.; Chen, D.; Gonzalez, J.; Grady, W.M. Battery energy storage for enabling integration of distributed solar power generation. IEEE Trans. Smart Grid 2012, 3, 850-857. [CrossRef]

207. Morstyn, T.; Hredzak, B.; Agelidis, V.G. Cooperative multi-agent control of heterogeneous storage devices distributed in a DC microgrid. IEEE Trans. Power Syst. 2016, 31, 2974-2986. [CrossRef]

208. Morstyn, T.; Savkin, A.V.; Hredzak, B.; Agelidis, V.G. Multi-agent sliding mode control for state of charge balancing between battery energy storage systems distributed in a DC Microgrid. IEEE Trans. Smart Grid 2018, 9, 4735-4743. [CrossRef]

209. Li, C.; Dragicevic, T.; Plaza, M.G.; Andrade, F.; Vasquez, J.C.; Guerrero, J.M. Multiagent based distributed control for state-of-charge balance of distributed energy storage in DC microgrids. In Proceedings of the IECON 2014-40th Annual Conference of the IEEE Industrial Electronics Society, Dallas, TX, USA, 29 October-1 November 2014; pp. 2180-2184.

210. Mohd, A.; Ortjohann, E.; Schmelter, A.; Hamsic, N.; Morton, D. Challenges in integrating distributed Energy storage systems into future smart grid. In Proceedings of the 2008 IEEE International Symposium on Industrial Electronics, Cambridge, UK, 30 June-2 July 2008; pp. 1627-1632.

211. Zhou, Y.; Li, X. Vehicle to grid technology: A review. In Proceedings of the 2015 34th Chinese Control Conference (CCC), Hangzhou, China, 28-30 July 2015; pp. 9031-9036.

212. Wenzel, G.; Negrete-Pincetic, M.; Olivares, D.E.; MacDonald, J.; Callaway, D.S. Real-time charging strategies for an electric vehicle aggregator to provide ancillary services. IEEE Trans. Smart Grid 2018, 9, 5141-5151. [CrossRef]

213. Aldik, A.; Al-Awami, A.T.; Sortomme, E.; Muqbel, A.M.; Shahidehpour, M. A planning model for electric vehicle aggregators providing ancillary services. IEEE Access 2018, 6, 70685-70697. [CrossRef]

214. Cheng, M.; Sami, S.S.; Wu, J. Virtual energy storage system for smart grids. Proc. Energy Procedia 2016, 88, 436-442. [CrossRef]

215. Kim, Y.; Raghunathan, V.; Raghunathan, A. Design and management of battery-supercapacitor hybrid electrical energy storage systems for regulation services. IEEE Trans. Multi-Scale Comput. Syst. 2017, 3, 12-24. [CrossRef]

216. Lucas, A.; Chondrogiannis, S. Smart grid energy storage controller for frequency regulation and peak shaving, using a vanadium redox flow battery. Int. J. Electr. Power Energy Syst. 2016, 80, 26-36. [CrossRef]

217. Morstyn, T.; Hredzak, B.; Agelidis, V.G. Distributed cooperative control of microgrid storage. IEEE Trans. Power Syst. 2015, 30, 2780-2789. [CrossRef]

218. Wang, R.; Wang, D.; Jia, H.; Yang, Z.; Qi, Y.; Fan, M.; Sheng, W.; Hou, L. A coordination control strategy of battery and virtual energy storage to smooth the micro-grid tie-line power fluctuations. Zhongguo Dianji Gongcheng XuebaoProceedings Chin. Soc. Electr. Eng. 2015, 35, 5124-5134. [CrossRef]

219. Palizban, O.; Kauhaniemi, K. Energy storage systems in modern grids-Matrix of technologies and applications. J. Energy Storage 2016, 6, 248-259. [CrossRef]

220. Rohit, A.K.; Devi, K.P.; Rangnekar, S. An overview of energy storage and its importance in Indian renewable energy sector: Part I-Technologies and Comparison. J. Energy Storage 2017, 13, 10-23. [CrossRef]

221. Alotaibi, I. A Hybridized SMES/BESS Optimal Storage System. Master's, Thesis, King Fahd University of Petroleum and Minerals, Dhahran, Saudi Arabia, 2018.

222. Avendano-Mora, M.; Camm, E.H. Financial assessment of battery energy storage systems for frequency regulation service. In Proceedings of the 2015 IEEE Power Energy Society General Meeting, Denver, CO, USA, 26-30 July 2015; pp. 1-5. 
223. Potdar, V.; Chandan, A.; Batool, S.; Patel, N. Big energy data management for smart grids-Issues, challenges and recent developments. Smart Cities 2018, 177-205. [CrossRef]

224. Ahsan, U.; Bais, A. Distributed big data management in smart grid. In Proceedings of the 2017 26th Wireless and Optical Communication Conference (WOCC), Newark, NJ, USA, 7-8 April 2017; pp. 1-6.

225. Daki, H.; Hannani, A.E.; Aqqal, A.; Haidine, A.; Dahbi, A. Big Data management in smart grid: Concepts, requirements and implementation. J. Big Data 2017, 4, 13. [CrossRef]

226. Diamantoulakis, P.D.; Kapinas, V.M.; Karagiannidis, G.K. Big data analytics for dynamic energy management in smart grids. Big Data Res. 2015, 2, 94-101. [CrossRef]

227. Gungor, V.C.; Sahin, D.; Kocak, T.; Ergut, S.; Buccella, C.; Cecati, C.; Hancke, G.P. Smart grid technologies: Communication technologies and standards. IEEE Trans. Ind. Inform. 2011, 7, 529-539. [CrossRef]

228. Zhou, K.; Fu, C.; Yang, S. Big data driven smart energy management: From big data to big insights. Renew. Sustain. Energy Rev. 2016, 56, 215-225. [CrossRef]

229. Zaballos, A.; Vallejo, A.; Selga, J.M. Heterogeneous communication architecture for the smart grid. IEEE Netw. 2011, 25, 30-37. [CrossRef]

230. Yin, J.; Kulkarni, A.; Purohit, S.; Gorton, I.; Akyol, B. Scalable real time data management for smart grid. In Proceedings of the Middleware 2011 Industry Track Workshop, Lisbon, Portugal, 7-11 December 2011; p. 1.

231. Hashem, I.A.T.; Chang, V.; Anuar, N.B.; Adewole, K.; Yaqoob, I.; Gani, A.; Ahmed, E.; Chiroma, H. The role of big data in smart city. Int. J. Inf. Manag. 2016, 36, 748-758. [CrossRef]

232. Vojdani, A. Smart integration. IEEE Power Energy Mag. 2008, 6, 71-79. [CrossRef]

233. He, X.; Ai, Q.; Qiu, R.C.; Huang, W.; Piao, L.; Liu, H. A big data architecture design for smart grids based on random matrix theory. IEEE Trans. Smart Grid 2017, 8, 674-686. [CrossRef]

234. Stimmel, C.L. Big Data Analytics Strategies for the Smart Grid; CRC Press: Boca Raton, FL, USA, 2014.

235. Gharaibeh, A.; Salahuddin, M.A.; Hussini, S.J.; Khreishah, A.; Khalil, I.; Guizani, M.; Al-Fuqaha, A. Smart cities: A survey on data management, security, and enabling technologies. IEEE Commun. Surv. Tutor. 2017, 19, 2456-2501. [CrossRef]

236. Uludag, S.; Lui, K.; Ren, W.; Nahrstedt, K. Secure and scalable data collection with time minimization in the smart grid. IEEE Trans. Smart Grid 2016, 7, 43-54. [CrossRef]

237. Australian Bureau of Statistics Dwelling Type (2017) Greater Sydney. In Id Popul Experts; Available online: http://profile.id.com.au/australia/dwellings?WebID=250 (accessed on 21 January 2019).

238. Huang, H.; Savkin, A.V. An energy efficient approach for data collection in wireless sensor networks using public transportation vehicles. AEU Int. J. Electron. Commun. 2017, 75, 108-118. [CrossRef]

239. Li, X.; Lv, Z.; Hu, J.; Zhang, B.; Shi, L.; Feng, S. XEarth: A 3D GIS platform for managing massive city information. In Proceedings of the 2015 IEEE International Conference on Computational Intelligence and Virtual Environments for Measurement Systems and Applications (CIVEMSA), Shenzhen, China, 12-14 June 2015; pp. 1-6.

240. Domínguez, J.; Amador, J. Geographical information systems applied in the field of renewable energy sources. Comput. Ind. Eng. 2007, 52, 322-326. [CrossRef]

241. Huang, H.; Savkin, A.V. Viable path planning for data collection robots in a sensing field with obstacles. Comput. Commun. 2017, 111, 84-96. [CrossRef]

242. Liu, N.; Chen, J.; Zhu, L.; Zhang, J.; He, Y. A key management scheme for secure communications of advanced metering infrastructure in smart grid. IEEE Trans. Ind. Electron. 2013, 60, 4746-4756. [CrossRef]

243. Uludag, S.; Zeadally, S.; Badra, M. Techniques, taxonomy, and challenges of privacy protection in the smart grid. In Privacy in a Digital, Networked World; Zeadally, S., Badra, M., Eds.; Springer International Publishing: Cham, Switzerland, 2015; pp. 343-390. ISBN 978-3-319-08469-5.

244. Fouda, M.M.; Fadlullah, Z.M.; Kato, N.; Lu, R.; Shen, X.S. A lightweight message authentication scheme for smart grid communications. IEEE Trans. Smart Grid 2011, 2, 675-685. [CrossRef]

245. Bekara, C.; Luckenbach, T.; Bekara, K. A Privacy Preserving and Secure Authentication Protocol for the Advanced Metering Infrastructure with Non-Repudiation Service. In Proceedings of the The Second International Conference on Smart Grids, St. Maarten, The Netherlands, 25-29 March 2012; p. 9.

246. Abbasinezhad-Mood, D.; Nikooghadam, M. An ultra-lightweight and secure scheme for communications of smart meters and neighborhood gateways by utilization of an ARM Cortex-M microcontroller. IEEE Trans. Smart Grid 2018, 9, 6194-6205. [CrossRef] 
247. Kim, Y.; Kolesnikov, V.; Kim, H.; Thottan, M. SSTP: A scalable and secure transport protocol for smart grid data collection. In Proceedings of the 2011 IEEE International Conference on Smart Grid Communications (SmartGridComm), Brussels, Belgium, 17-20 October 2011; pp. 161-166.

248. Saputro, N.; Akkaya, K. Investigation of smart meter data reporting strategies for optimized performance in smart grid AMI networks. IEEE Internet Things J. 2017, 4, 894-904. [CrossRef]

249. Cody, R. Cody's Data Cleaning Techniques Using SAS. In Cody's Data Cleaning Techniques Using SAS, 3rd ed.; SAS Institute Inc.: Cary, NC, USA, 2017; p. 23. ISBN 978-1-63526-069-4.

250. Chu, X.; Ilyas, I.F. Qualitative data cleaning. Proc. VLDB Endow. 2016, 9, 1605-1608. [CrossRef]

251. Sagiroglu, S.; Terzi, R.; Canbay, Y.; Colak, I. Big data issues in smart grid systems. In Proceedings of the 2016 IEEE International Conference on Renewable Energy Research and Applications (ICRERA), Birmingham, UK, 20-23 November 2016; pp. 1007-1012.

252. Dellino, G.; Laudadio, T.; Mari, R.; Mastronardi, N.; Meloni, C.; Vergura, S. Energy production forecasting in a PV plant using transfer function models. In Proceedings of the 2015 IEEE 15th International Conference on Environment and Electrical Engineering (EEEIC), Rome, Italy, 10-13 June 2015; pp. 1379-1383.

253. Xie, S.; Chen, Z. Anomaly detection and redundancy elimination of big sensor data in internet of things. arXiv 2017, arXiv:1703.03225.

254. Lee, K.; Kim, D.; Shin, I. REboost: Improving throughput in wireless networks using redundancy elimination. IEEE Commun. Lett. 2017, 21, 160-163. [CrossRef]

255. Chen, W.; Zhou, K.; Yang, S.; Wu, C. Data quality of electricity consumption data in a smart grid environment. Renew. Sustain. Energy Rev. 2017, 75, 98-105. [CrossRef]

256. Aiello, M.; Pagani, G.A. The smart grid's data generating potentials. In Proceedings of the 2014 Federated Conference on Computer Science and Information Systems, Warsaw, Poland, 7-10 September 2014; pp. 9-16.

257. Li, F.; Luo, B.; Liu, P. Secure information aggregation for smart grids using homomorphic encryption. In Proceedings of the First IEEE International Conference on Smart Grid Communications, Gaithersburg, MD, USA, 4-6 October 2010; pp. 327-332.

258. Uddin, F. Energy-Aware optimal data aggregation in smart grid wireless communication networks. IEEE Trans. Green Commun. Netw. 2017, 1, 358-371. [CrossRef]

259. Groat, M.M.; Hey, W.; Forrest, S. KIPDA: K-indistinguishable privacy-preserving data aggregation in wireless sensor networks. In Proceedings of the IEEE INFOCOM, Shanghai, China, 10-15 April 2011; pp. 2024-2032.

260. Rottondi, C.; Verticale, G.; Krauss, C. Distributed privacy-preserving aggregation of metering data in smart grids. IEEE J. Sel. Areas Commun. 2013, 31, 1342-1354. [CrossRef]

261. Li, F.; Luo, B. Preserving data integrity for smart grid data aggregation. In Proceedings of the 2012 IEEE Third International Conference on Smart Grid Communications (SmartGridComm), Tainan, Taiwan, 5-8 November 2012; pp. 366-371.

262. Guerrero, J.I.; García, A.; Personal, E.; Luque, J.; León, C. Heterogeneous data source integration for smart grid ecosystems based on metadata mining. Expert Syst. Appl. 2017, 79, 254-268. [CrossRef]

263. Alahakoon, D.; Yu, X. Smart electricity meter data intelligence for future energy systems: A survey. IEEE Trans. Ind. Inform. 2016, 12, 425-436. [CrossRef]

264. Jurado, S.; Nebot, À.; Mugica, F.; Mihaylov, M. Fuzzy inductive reasoning forecasting strategies able to cope with missing data: A smart grid application. Appl. Soft Comput. 2017, 51, 225-238. [CrossRef]

265. Qiu, R.C.; Antonik, P. Smart Grid using big data analytics: A random matrix theory approach. In Smart Grid using Big Data Analytics; John Wiley \& Sons, Ltd.: Chichester, UK, 2017; pp. 1-575. ISBN 978-1-118-71677-9.

266. Sigeru, O.; Sara, R. Distributed Computing and Artificial Intelligence, 14th International Conference; Springer International Publishing AG: Cham, Switzerland, 2017; ISBN 978-3-319-62409-9.

267. Virgilio, R.D. Smart RDF Data Storage in Graph Databases. In Proceedings of the 2017 17th IEEE/ACM International Symposium on Cluster, Cloud and Grid Computing (CCGRID), Madrid, Spain, 14-17 May 2017; pp. 872-881.

268. Bruno, S.; Dellino, G.; Scala, M.L.; Meloni, C. A microforecasting module for energy consumption in smart grids. In Proceedings of the 2018 IEEE International Conference on Environment and Electrical Engineering and 2018 IEEE Industrial and Commercial Power Systems Europe (EEEIC/I\&CPS Europe), Palermo, Italy, 12-15 June 2018; pp. 1-6. 
269. Monika; Srinivasan, D.; Reindl, T. Real-time display of data from a smart-grid on geographical map using a GIS tool and its role in optimization of game theory. In Proceedings of the 2015 IEEE Innovative Smart Grid Technologies-Asia (ISGT ASIA), Bangkok, Thailand, 3-6 November 2015; pp. 1-6.

270. Stefan, M.; Lopez, J.G.; Andreasen, M.H.; Olsen, R.L. Visualization techniques for electrical grid smart metering data: A survey. In Proceedings of the 2017 IEEE Third International Conference on Big Data Computing Service and Applications (BigDataService), San Francisco, CA, USA, 6-9 April 2017; pp. 165-171.

271. Yu, M.; Hong, S.H. A real-time demand-response algorithm for smart grids: A stackelberg game approach. IEEE Trans. Smart Grid 2016, 7, 879-888. [CrossRef]

272. Siano, P. Demand response and smart grids-A survey. Renew. Sustain. Energy Rev. 2014, 30, 461-478. [CrossRef]

273. Colson, C.M.; Nehrir, M.H. Comprehensive real-time microgrid power management and control with distributed agents. IEEE Trans. Smart Grid 2013, 4, 617-627. [CrossRef]

274. Ashok, A.; Hahn, A.; Govindarasu, M. Cyber-physical security of wide-area monitoring, protection and control in a smart grid environment. J. Adv. Res. 2014, 5, 481-489. [CrossRef]

275. Aloul, F.; Al-Ali, A.R.; Al-Dalky, R.; Al-Mardini, M.; El-Hajj, W. Smart grid security: Threats, vulnerabilities and solutions. Int. J. Smart Grid Clean Energy 2012, 1-6. [CrossRef]

276. Ding, D.; Han, Q.-L.; Xiang, Y.; Ge, X.; Zhang, X.-M. A survey on security control and attack detection for industrial cyber-physical systems. Neurocomputing 2018, 275, 1674-1683. [CrossRef]

277. Gupta, A.; Anpalagan, A.; Carvalho, G.H.; Guan, L.; Woungang, I. Prevailing and emerging cyber threats and security practices in iot-enabled smart grids: A survey. J. Netw. Comput. Appl. 2019, 132, 118-148. [CrossRef]

278. Peng, C.; Sun, H.; Yang, M.; Wang, Y.-L. A survey on security communication and control for smart grids under malicious cyber attacks. IEEE Trans. Syst. Man Cybern. Syst. 2019, 49, 1554-1569. [CrossRef]

279. Li, B. Detection of False Data Injection Attacks in Smart Grid Cyber-Physical Systems. Ph.D. Thesis, Nanyang Technological University, Singapore, 2019.

280. Li, X.; Liang, X.; Lu, R.; Shen, X.; Lin, X.; Zhu, H. Securing smart grid: Cyber attacks, countermeasures, and challenges. IEEE Commun. Mag. 2012, 50, 38-45. [CrossRef]

281. Wang, W.; Lu, Z. Cyber security in the smart grid: Survey and challenges. Comput. Netw. 2013, 57, 1344-1371. [CrossRef]

282. Liu, J.; Xiao, Y.; Li, S.; Liang, W.; Chen, C.P. Cyber security and privacy issues in smart grids. IEEE Commun. Surv. Tutor. 2012, 14, 981-997. [CrossRef]

283. Khurana, H.; Hadley, M.; Lu, N.; Frincke, D.A. Smart-grid security issues. IEEE Secur. Priv. 2010, 8, 81-85. [CrossRef]

284. Liang, G.; Zhao, J.; Luo, F.; Weller, S.R.; Dong, Z.Y. A review of false data injection attacks against modern power systems. IEEE Trans. Smart Grid 2017, 8, 1630-1638. [CrossRef]

285. Giraldo, J.; Sarkar, E.; Cardenas, A.A.; Maniatakos, M.; Kantarcioglu, M. Security and privacy in cyber-physical systems: A survey of surveys. IEEE Des. Test 2017, 34,7-17. [CrossRef]

286. Baig, Z.A.; Szewczyk, P.; Valli, C.; Rabadia, P.; Hannay, P.; Chernyshev, M.; Johnstone, M.; Kerai, P.; Ibrahim, A.; Sansurooah, K. Future challenges for smart cities: Cyber-security and digital forensics. Digit. Investig. 2017, 22, 3-13. [CrossRef]

287. Zhang, K.; Ni, J.; Yang, K.; Liang, X.; Ren, J.; Shen, X.S. Security and privacy in smart city applications: Challenges and solutions. IEEE Commun. Mag. 2017, 55, 122-129. [CrossRef]

288. Boroojeni, K.G.; Amini, M.H.; Iyengar, S.S. Smart Grids: Security and Privacy Issues; Springer: Cham, Switzerland, 2017.

289. Liang, G.; Weller, S.R.; Zhao, J.; Luo, F.; Dong, Z.Y. The 2015 ukraine blackout: Implications for false data injection attacks. IEEE Trans. Power Syst. 2017, 32, 3317-3318. [CrossRef]

290. Wang, D.; Wang, Z.; Shen, B.; Alsaadi, F.E.; Hayat, T. Recent advances on filtering and control for cyber-physical systems under security and resource constraints. J. Frankl. Inst. 2016, 11, 2451-2466. [CrossRef]

291. Li, X.; Scaglione, A. Robust decentralized state estimation and tracking for power systems via network gossiping. IEEE J. Sel. Areas Commun. 2013, 31, 1184-1194. [CrossRef]

292. Pang, Z.H.; Liu, G.P.; Dong, Z. Secure networked control systems under denial of service attacks. IFAC Proc. Vol. 2011, 44, 8908-8913. [CrossRef]

293. Shoukry, Y.; Tabuada, P. Event-triggered state observers for sparse sensor noise/attacks. IEEE Trans. Autom. Control 2016, 61, 2079-2091. [CrossRef] 
294. Amin, S.; Schwartz, G.A.; Shankar Sastry, S. Security of interdependent and identical networked control systems. Automatica 2013, 49, 186-192. [CrossRef]

295. Befekadu, G.K.; Gupta, V.; Antsaklis, P.J. Risk-sensitive control under markov modulated denial-of-service (DoS) attack strategies. IEEE Trans. Autom. Control 2015, 60, 3299-3304. [CrossRef]

296. Zhang, X.-M.; Han, Q.-L.; Seuret, A.; Gouaisbaut, F. An improved reciprocally convex inequality and an augmented Lyapunov-Krasovskii functional for stability of linear systems with time-varying delay. Automatica 2017, 84, 221-226. [CrossRef]

297. Wang, J.; Zhang, X.; Han, Q. Event-triggered generalized dissipativity filtering for neural networks with time-varying delays. IEEE Trans. Neural Netw. Learn. Syst. 2016, 27, 77-88. [CrossRef]

298. Chenine, M.; Ullberg, J.; Nordström, L.; Wu, Y.; Ericsson, G.N. A framework for wide-area monitoring and control systems interoperability and cybersecurity analysis. IEEE Trans. Power Deliv. 2014, 29, 633-641. [CrossRef]

299. Lee, P.; Clark, A.; Bushnell, L.; Poovendran, R. A passivity framework for modeling and mitigating wormhole attacks on networked control systems. IEEE Trans. Autom. Control 2014, 59, 3224-3237. [CrossRef]

300. Ding, D.; Wang, Z.; Han, Q.; Wei, G. Security control for discrete-time stochastic nonlinear systems subject to deception attacks. IEEE Trans. Syst. Man Cybern. Syst. 2018, 48, 779-789. [CrossRef]

301. Ding, D.; Wang, Z.; Ho, D.W.C.; Wei, G. Observer-based event-triggering consensus control for multiagent systems with lossy sensors and cyber-attacks. IEEE Trans. Cybern. 2017, 47, 1936-1947. [CrossRef] [PubMed]

302. Singh, S.K.; Khanna, K.; Bose, R.; Panigrahi, B.K.; Joshi, A. Joint-transformation-based detection of false data injection attacks in smart grid. IEEE Trans. Ind. Inform. 2018, 14, 89-97. [CrossRef]

303. Rai, A.; Ward, D.; Roy, S.; Warnick, S. Vulnerable links and secure architectures in the stabilization of networks of controlled dynamical systems. In Proceedings of the 2012 American Control Conference (ACC), Montreal, QC, Canada, 27-29 June 2012; pp. 1248-1253.

304. Chen, J.; Abur, A. Placement of PMUs to enable bad data detection in state estimation. IEEE Trans. Power Syst. 2006, 21, 1608-1615. [CrossRef]

305. Ashok, A.; Govindarasu, M.; Ajjarapu, V. Online detection of stealthy false data injection attacks in power system state estimation. IEEE Trans. Smart Grid 2018, 9, 1636-1646. [CrossRef]

306. Hao, J.; Piechocki, R.J.; Kaleshi, D.; Chin, W.H.; Fan, Z. Sparse malicious false data injection attacks and defense mechanisms in smart grids. IEEE Trans. Ind. Inform. 2015, 11, 1-12. [CrossRef]

307. Tommaso, A.O.D.; Favuzza, S.; Genduso, F.; Miceli, R.; Galluzzo, G.R. Development of diagnostic systems for the fault tolerant operation of Micro-Grids. In Proceedings of the SPEEDAM, Pisa, Italy, 14-16 June 2010; pp. $1645-1650$.

308. Kailkhura, B.; Han, Y.S.; Brahma, S.; Varshney, P.K. Distributed bayesian detection in the presence of byzantine data. IEEE Trans. Signal Process. 2015, 63, 5250-5263. [CrossRef]

309. Kailkhura, B.; Han, Y.S.; Brahma, S.; Varshney, P.K. Asymptotic analysis of distributed bayesian detection with byzantine data. IEEE Signal Process. Lett. 2015, 22, 608-612. [CrossRef]

310. Rawat, A.S.; Anand, P.; Chen, H.; Varshney, P.K. Collaborative spectrum sensing in the presence of byzantine attacks in cognitive radio networks. IEEE Trans. Signal Process. 2011, 59, 774-786. [CrossRef]

311. Deng, R.; Xiao, G.; Lu, R. Defending against false data injection attacks on power system state estimation. IEEE Trans. Ind. Inform. 2017, 13, 198-207. [CrossRef]

312. Huang, Y.; Tang, J.; Cheng, Y.; Li, H.; Campbell, K.A.; Han, Z. Real-time detection of false data injection in smart grid networks: An adaptive CUSUM method and analysis. IEEE Syst. J. 2016, 10, 532-543. [CrossRef]

313. Hug, G.; Giampapa, J.A. Vulnerability assessment of AC state estimation with respect to false data injection cyber-attacks. IEEE Trans. Smart Grid 2012, 3, 1362-1370. [CrossRef]

314. Liu, L.; Esmalifalak, M.; Ding, Q.; Emesih, V.A.; Han, Z. Detecting false data injection attacks on power grid by sparse optimization. IEEE Trans. Smart Grid 2014, 5, 612-621. [CrossRef]

315. Manandhar, K.; Cao, X.; Hu, F.; Liu, Y. Detection of Faults and Attacks Including False Data Injection Attack in Smart Grid Using Kalman Filter. IEEE Trans. Control Netw. Syst. 2014, 1, 370-379. [CrossRef]

316. Mo, Y.; Chabukswar, R.; Sinopoli, B. Detecting Integrity Attacks on SCADA Systems. IEEE Trans. Control Syst. Technol. 2014, 22, 1396-1407. [CrossRef]

317. Ao, W.; Song, Y.; Wen, C. Adaptive cyber-physical system attack detection and reconstruction with application to power systems. IET Control Theory Appl. 2016, 10, 1458-1468. [CrossRef] 
318. Pasqualetti, F.; Dörfler, F.; Bullo, F. Attack detection and Identification in cyber-physical systems. IEEE Trans. Autom. Control 2013, 58, 2715-2729. [CrossRef]

319. Sun, C.-C.; Hahn, A.; Liu, C.-C. Cyber security of a power grid: State-of-the-art. Int. J. Electr. Power Energy Syst. 2018, 99, 45-56. [CrossRef]

320. Ericsson, G.N. Toward a framework for managing information security for an electric power utility-CIGRÉ experiences. IEEE Trans. Power Deliv. 2007, 22, 1461-1469. [CrossRef]

321. Kushner, D. The real story of stuxnet. IEEE Spectr. 2013, 50, 48-53. [CrossRef]

322. Falliere, N.; Murchu, L.O.; Chien, E. W32. Stuxnet Dossier. White Pap. Symantec Corp Secur. Response $2011,5,69$.

323. Ten, C.; Liu, C.; Manimaran, G. Vulnerability assessment of cybersecurity for SCADA systems. IEEE Trans. Power Syst. 2008, 23, 1836-1846. [CrossRef]

324. Namboodiri, V.; Aravinthan, V.; Mohapatra, S.N.; Karimi, B.; Jewell, W. Toward a secure wireless-based home area network for metering in smart grids. IEEE Syst. J. 2014, 8, 509-520. [CrossRef]

325. Liang, X.; Li, X.; Lu, R.; Lin, X.; Shen, X. UDP: Usage-based dynamic pricing with privacy preservation for smart grid. IEEE Trans. Smart Grid 2013, 4, 141-150. [CrossRef]

326. Sahoo, S.; Nikovski, D.; Muso, T.; Tsuru, K. Electricity theft detection using smart meter data. In Proceedings of the 2015 IEEE Power Energy Society Innovative Smart Grid Technologies Conference (ISGT), Washington, DC, USA, 18-20 February 2015; pp. 1-5.

327. Bishop, A.N.; Savkin, A.V. Set-valued state estimation and attack detection for uncertain descriptor systems. IEEE Signal Process. Lett. 2013, 20, 1102-1105. [CrossRef]

328. Yang, Y.; McLaughlin, K.; Sezer, S.; Littler, T.; Im, E.G.; Pranggono, B.; Wang, H.F. Multiattribute SCADA-specific intrusion detection system for power networks. IEEE Trans. Power Deliv. 2014, 29, 1092-1102. [CrossRef]

329. Zhang, Y.; Wang, L.; Sun, W.; II, R.C.G.; Alam, M. Distributed intrusion detection system in a multi-layer network architecture of smart grids. IEEE Trans. Smart Grid 2011, 2, 796-808. [CrossRef]

330. Yang, Y.; McLaughlin, K.; Littler, T.; Sezer, S.; Pranggono, B.; Wang, H.F. Intrusion detection system for IEC 60870-5-104 based SCADA networks. In Proceedings of the IEEE Power Energy Society General Meeting, Vancouver, BC, Canada, 21-25 July 2013; pp. 1-5.

331. Ten, C.; Hong, J.; Liu, C. Anomaly detection for cybersecurity of the substations. IEEE Trans. Smart Grid 2011, 2, 865-873. [CrossRef]

332. Hahn, A.; Govindarasu, M. Model-based intrustion detection for the smart grid (MINDS). In Proceedings of the Eighth Annual Cyber Security and Information Intelligence Research Workshop, New York, NY, USA, 8-10 January 2013; pp. 27:1-27:4.

333. Hong, J.; Liu, C.; Govindarasu, M. Integrated anomaly detection for cyber security of the substations. IEEE Trans. Smart Grid 2014, 5, 1643-1653. [CrossRef]

334. Yang, Y.; Xu, H.; Gao, L.; Yuan, Y.; McLaughlin, K.; Sezer, S. Multidimensional intrusion detection system for IEC 61850-based SCADA networks. IEEE Trans. Power Deliv. 2017, 32, 1068-1078. [CrossRef]

335. Premaratne, U.K.; Samarabandu, J.; Sidhu, T.S.; Beresh, R.; Tan, J. An intrusion detection system for IEC61850 automated substations. IEEE Trans. Power Deliv. 2010, 25, 2376-2383. [CrossRef]

336. Wu, J.; Xiong, J.; Shil, P.; Shi, Y. Real time anomaly detection in wide area monitoring of smart grids. In Proceedings of the IEEE/ACM International Conference on Computer-Aided Design (ICCAD), San Jose, CA, USA, 2-6 November 2014; pp. 197-204.

337. Fan, Y.; Zhang, Z.; Trinkle, M.; Dimitrovski, A.D.; Song, J.B.; Li, H. A cross-layer defense mechanism against GPS spoofing attacks on PMUs in smart grids. IEEE Trans. Smart Grid 2015, 6, 2659-2668. [CrossRef]

338. Mitchell, R.; Chen, I. Behavior-rule based intrusion detection systems for safety critical smart grid applications. IEEE Trans. Smart Grid 2013, 4, 1254-1263. [CrossRef]

339. McLaughlin, S.; Holbert, B.; Fawaz, A.; Berthier, R.; Zonouz, S. A multi-sensor energy theft detection framework for advanced metering infrastructures. IEEE J. Sel. Areas Commun. 2013, 31, 1319-1330. [CrossRef]

340. Liu, Y.; Hu, S.; Ho, T. Leveraging strategic detection techniques for smart home pricing cyberattacks. IEEE Trans. Dependable Secure Comput. 2016, 13, 220-235. [CrossRef]

341. Liu, X.; Zhu, P.; Zhang, Y.; Chen, K. A collaborative intrusion detection mechanism against false data injection attack in advanced metering infrastructure. IEEE Trans. Smart Grid 2015, 6, 2435-2443. [CrossRef] 
342. Berthier, R.; Sanders, W.H. Specification-based intrusion detection for advanced metering infrastructures. In Proceedings of the IEEE 17th Pacific Rim International Symposium on Dependable Computing, Pasadena, CA, USA, 12-14 December 2011; pp. 184-193.

343. Pultarova, T. Cyber security-Ukraine grid hack is wake-up call for network operators [News Briefing]. Eng. Technol. 2016, 11, 12-13. [CrossRef]

344. Min, C.-G.; Park, J.; Hur, D.; Kim, M.-K. The economic viability of renewable portfolio standard support for offshore wind farm projects in korea. Energies 2015, 8, 9731-9750. [CrossRef]

345. Nwaeze, E.T. Deregulation of the electric power industry: The earnings, risk, and return effects. J. Regul. Econ. 2000, 19.

346. Kirschen, D.; Strbac, G. Fundamentals of Power System Economics: Kirschen/Power System Economics; John Wiley \& Sons, Ltd.: Chichester, UK, 2004.

347. Cory, B. Power System Restructuring and Deregulation: Trading, Performance and information Technology; John Wiley Sons: Chichester, UK, 2002; Volume 16.

348. Min, C.-G.; Kim, M.-K. Impact of the complementarity between variable generation resources and load on the flexibility of the Korean power system. Energies 2017, 10, 1719. [CrossRef]

349. Abhyankar, A.R.; Khaparde, S.A. Introduction to Deregulation in Power Industry; Indian Institute of Technology: Mumbai, India, 2013; p. 28.

350. Khalid, M.; Aguilera, R.P.; Savkin, A.V.; Agelidis, V.G. A market-oriented wind power dispatch strategy using adaptive price thresholds and battery energy storage. Wind Energy 2018, 21, 242-254. [CrossRef]

351. Ko, W.; Park, J.-K.; Kim, M.-K.; Heo, J.-H. A multi-energy system expansion planning method using a linearized load-energy curve: A case study in South Korea. Energies 2017, 10, 1663. [CrossRef]

352. Balijepalli, V.S.K.M.; Pradhan, V.; Khaparde, S.A.; Shereef, R.M. Review of demand response under smart grid paradigm. In Proceedings of the ISGT2011, Kollam, Kerala, India, 1-3 December 2011; pp. $236-243$.

353. Cavoukian, A.; Polonetsky, J.; Wolf, C. SmartPrivacy for the Smart Grid: Embedding privacy into the design of electricity conservation. Identity Inf. Soc. 2010, 3, 275-294. [CrossRef]

354. Li, R.; Wang, Z.; Gu, C.; Li, F.; Wu, H. A novel time-of-use tariff design based on Gaussian Mixture Model. Appl. Energy 2016, 162, 1530-1536. [CrossRef]

355. Herter, K.; McAuliffe, P.; Rosenfeld, A. An exploratory analysis of California residential customer response to critical peak pricing of electricity. Energy 2007, 32, 25-34. [CrossRef]

356. Khalid, A.; Javaid, N.; Mateen, A.; Ilahi, M.; Saba, T.; Rehman, A. Enhanced time-of-use electricity price rate using game theory. Electronics 2019, 8, 48. [CrossRef]

357. Celebi, E.; Fuller, J.D. Time-of-use pricing in electricity markets under different market structures. IEEE Trans. Power Syst. 2012, 27, 1170-1181. [CrossRef]

358. Ali, S.Q.; Maqbool, S.D.; Ahamed, T.P.I.; Malik, N.H. Load scheduling with maximum demand and time of use pricing for microgrids. In Proceedings of the 2013 IEEE Global Humanitarian Technology Conference: South Asia Satellite (GHTC-SAS), Trivandrum, India, 23-24 August 2013; pp. 234-238.

359. Liu, H.; Mahmoudi, N.; Chen, K. Microgrids real-time pricing based on clustering techniques. Energies 2018, 11, 1388. [CrossRef]

360. Caramanis, M.C.; Bohn, R.E.; Schweppe, F.C. Optimal spot pricing: Practice and theory. IEEE Trans. Power Appar. Syst. 1982, PAS-101, 3234-3245. [CrossRef]

361. Tang, Q.; Yang, K.; Zhou, D.; Luo, Y.; Yu, F. A real-time dynamic pricing algorithm for smart grid with unstable energy providers and malicious users. IEEE Internet Things J. 2016, 3, 554-562. [CrossRef]

362. Anees, A.; Chen, Y.-P.P. True real time pricing and combined power scheduling of electric appliances in residential energy management system. Appl. Energy 2016, 165, 592-600. [CrossRef]

363. Farrokhifar, M.; Momayyezi, F.; Sadoogi, N.; Safari, A. Real-time based approach for intelligent building energy management using dynamic price policies. Sustain. Cities Soc. 2018, 37, 85-92. [CrossRef]

364. Eissa, M.M. First time real time incentive demand response program in smart grid with "i-Energy" management system with different resources. Appl. Energy 2018, 212, 607-621. [CrossRef]

365. Kim, S.; Giannakis, G.B. Real-time electricity pricing for demand response using online convex optimization. In Proceedings of the ISGT, Washington, DC, USA, 19-22 February 2014; pp. 1-5.

366. Mohsenian-Rad, A.; Leon-Garcia, A. Optimal residential load control with price prediction in real-time electricity pricing environments. IEEE Trans. Smart Grid 2010, 1, 120-133. [CrossRef] 
367. Li, P.; Wang, H.; Zhang, B. A distributed online pricing strategy for demand response programs. IEEE Trans. Smart Grid 2019, 10, 350-360. [CrossRef]

368. Oldewurtel, F.; Ulbig, A.; Parisio, A.; Andersson, G.; Morari, M. Reducing peak electricity demand in building climate control using real-time pricing and model predictive control. In Proceedings of the 49th IEEE Conference on Decision and Control (CDC), Atlanta, GA, USA, 15-17 December 2010; pp. 1927-1932.

369. Lujano-Rojas, J.M.; Monteiro, C.; Dufo-López, R.; Bernal-Agustín, J.L. Optimum residential load management strategy for real time pricing (RTP) demand response programs. Energy Policy 2012, 45, 671-679. [CrossRef]

370. Zhu, H.; Gao, Y.; Hou, Y.; Wang, Z.; Feng, X. Real-time pricing considering different type of smart home appliances based on markov decision process. Int. J. Electr. Power Energy Syst. 2019, 107, 486-495. [CrossRef]

371. Wang, Y.; Li, L. Critical peak electricity pricing for sustainable manufacturing: Modeling and case studies. Appl. Energy 2016, 175, 40-53. [CrossRef]

372. Park, S.C.; Jin, Y.G.; Song, H.Y.; Yoon, Y.T. Designing a critical peak pricing scheme for the profit maximization objective considering price responsiveness of customers. Energy 2015, 83, 521-531. [CrossRef]

373. Kato, T.; Tokuhara, A.; Ushifusa, Y.; Sakurai, A.; Aramaki, K.; Maruyama, F. Consumer responses to critical peak pricing: Impacts of maximum electricity-saving behavior. Electr. J. 2016, 29, 12-19. [CrossRef]

374. Javaid, N.; Ahmed, A.; Iqbal, S.; Ashraf, M. Day ahead real time pricing and critical peak pricing based power scheduling for smart homes with different duty cycles. Energies 2018, 11, 1464. [CrossRef]

375. Bagher Sadati, S.M.; Moshtagh, J.; Shafie-khah, M.; Rastgou, A.; Catalão, J.P.S. Operational scheduling of a smart distribution system considering electric vehicles parking lot: A bi-level approach. Int. J. Electr. Power Energy Syst. 2019, 105, 159-178. [CrossRef]

376. Zhang, Y.; Islam, M.M.; Sun, Z.; Yang, S.; Dagli, C.; Xiong, H. Optimal sizing and planning of onsite generation system for manufacturing in Critical Peaking Pricing demand response program. Int. J. Prod. Econ. 2018, 206, 261-267. [CrossRef]

377. Osorio, G.J.; Shafie-Khah, M.; Soares, N.G.S.; Catalao, J.P.S. Optimal dynamic tariffs for flexible ramp market in the presence of wind power generation and demand response. In Proceedings of the IEEE International Conference on Environment and Electrical Engineering and IEEE Industrial and Commercial Power Systems Europe (EEEIC/I\&CPS Europe), Palermo, Italy, 12-15 June 2018; pp. 1-5.

378. Doostizadeh, M.; Ghasemi, H. A day-ahead electricity pricing model based on smart metering and demand-side management. Energy 2012, 46, 221-230. [CrossRef]

379. Joe-Wong, C.; Sen, S.; Ha, S.; Chiang, M. Optimized day-ahead pricing for smart grids with device-specific scheduling flexibility. IEEE J. Sel. Areas Commun. 2012, 30, 1075-1085. [CrossRef]

380. Zhang, Q.; Raman, G.; Peng, J.C.-H. EV charging optimization based on day-ahead pricing incorporating consumer behavior. arXiv 2019, arXiv:190104675.

381. Philipsen, R.; Morales-España, G.; De Weerdt, M.; De Vries, L. Trading power instead of energy in day-ahead electricity markets. Appl. Energy 2019, 233-234, 802-815. [CrossRef]

382. Esmaeili, S.; Anvari-Moghaddam, A.; Jadid, S.; Guerrero, J.M. Optimal simultaneous day-ahead scheduling and hourly reconfiguration of distribution systems considering responsive loads. Int. J. Electr. Power Energy Syst. 2019, 104, 537-548. [CrossRef]

383. Subramanian, V.; Das, T.K. A two-layer model for dynamic pricing of electricity and optimal charging of electric vehicles under price spikes. Energy 2019, 167, 1266-1277. [CrossRef]

384. Kii, M.; Sakamoto, K.; Hangai, Y.; Doi, K. The effects of critical peak pricing for electricity demand management on home-based trip generation. IATSS Res. 2014, 37, 89-97. [CrossRef]

385. Jang, D.; Eom, J.; Kim, M.G.; Rho, J.J. Demand responses of Korean commercial and industrial businesses to critical peak pricing of electricity. J. Clean. Prod. 2015, 90, 275-290. [CrossRef]

386. Min, C.-G.; Kim, Y.C.; Kim, D.-H.; Kim, M.-K.; Park, J.-K. A study on coordinated generation maintenance scheduling in competitive electricity markets. J. Int. Counc. Electr. Eng. 2011, 1, 169-174. [CrossRef]

387. Zhuo, W.; Savkin, A.V. Profit maximizing control of a microgrid with renewable generation and BESS based on a battery cycle life model and energy price forecasting. Energies 2019, 12, 2904. [CrossRef]

388. Khalid, M.; Aguilera, R.P.; Savkin, A.V.; Agelidis, V.G. On maximizing profit of wind-battery supported power station based on wind power and energy price forecasting. Appl. Energy 2018, 211, 764-773. [CrossRef]

389. Kim, M.-K. Dynamic market-clearing model in a hybrid power market using parallel processing. J. Energy Eng. 2017, 143, 04016033. [CrossRef] 
390. Yang, Y.; Wang, M.; Liu, Y.; Zhang, L. Peak-off-peak load shifting: Are public willing to accept the peak and off-peak time of use electricity price? J. Clean. Prod. 2018, 199, 1066-1071. [CrossRef]

391. Yang, P.; Tang, G.; Nehorai, A. A game-theoretic approach for optimal time-of-use electricity pricing. IEEE Trans. Power Syst. 2013, 28, 884-892. [CrossRef]

392. Ferreira, R.d.S.; Barroso, L.A.; Lino, P.R.; Carvalho, M.M.; Valenzuela, P. Time-of-use tariff design under uncertainty in price-elasticities of electricity demand: A stochastic optimization approach. IEEE Trans. Smart Grid 2013, 4, 2285-2295. [CrossRef]

393. Herter, K. Residential implementation of critical-peak pricing of electricity. Energy Policy 2007, 35, 2121-2130. [CrossRef]

394. Nge, C.L.; Ranaweera, I.U.; Midtgård, O.-M.; Norum, L. A real-time energy management system for smart grid integrated photovoltaic generation with battery storage. Renew. Energy 2019, 130, 774-785. [CrossRef]

395. Centolella, P. The integration of price responsive demand into regional transmission organization (RTO) wholesale power markets and system operations. Energy 2010, 35, 1568-1574. [CrossRef]

396. Aalami, H.A.; Moghaddam, M.P.; Yousefi, G.R. Demand response modeling considering interruptible/curtailable loads and capacity market programs. Appl. Energy 2010, 87, 243-250. [CrossRef]

397. Moghaddam, M.P.; Abdollahi, A.; Rashidinejad, M. Flexible demand response programs modeling in competitive electricity markets. Appl. Energy 2011, 88, 3257-3269. [CrossRef]

398. Bruno, S.; Dellino, G.; La Scala, M.; Meloni, C. A microforecasting module for energy management in residential and tertiary buildings. Energies 2019, 12, 1006. [CrossRef]

399. Hwang, S.-H.; Kim, M.-K.; Ryu, H.-S. Real levelized cost of energy with indirect costs and market value of variable renewables: A study of the Korean power market. Energies 2019, 12, 2459. [CrossRef]

Publisher's Note: MDPI stays neutral with regard to jurisdictional claims in published maps and institutional affiliations. 